The North American Breeding Bird Survey in Mexico, 2008 to 2018-A Status Report

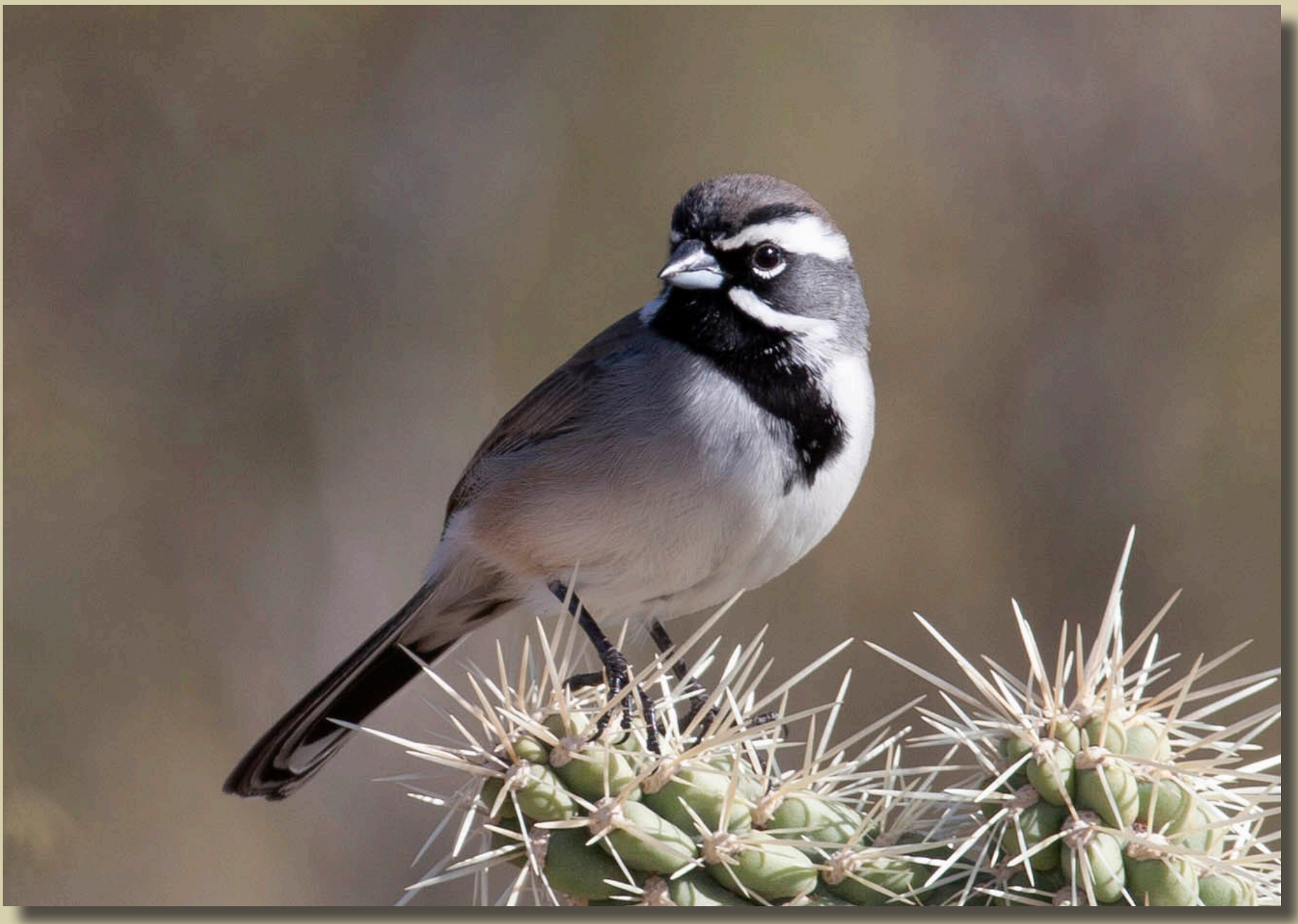

Circular 1479

U.S. Department of the Interior

U.S. Geological Survey 
Cover Amphispiza bilineata (Black-throated Sparrow), photograph by Bill Hubick, used with permission. 


\section{The North American Breeding Bird Survey in Mexico, 2008 to 2018-A Status Report}

By U.S. Geological Survey and Mexican National Commission for the

Knowledge and Use of Biodiversity

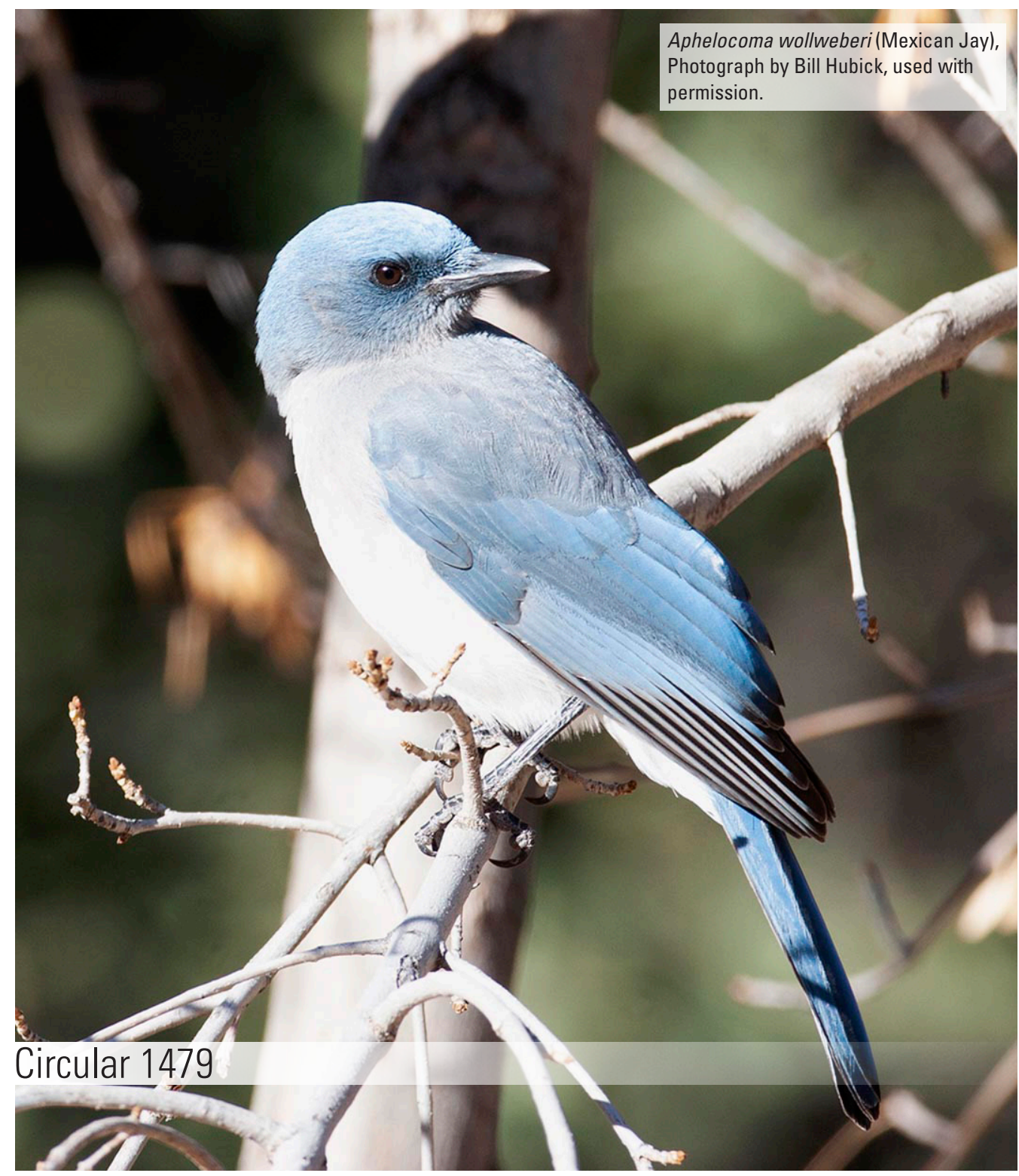

U.S. Department of the Interior

U.S. Geological Survey 


\section{U.S. Geological Survey, Reston, Virginia: 2021}

For more information on the USGS — the Federal source for science about the Earth, its natural and living resources, natural hazards, and the environment-visit https://www.usgs.gov or call 1-888-ASK-USGS.

For an overview of USGS information products, including maps, imagery, and publications, visit https://store.usgs.gov.

Any use of trade, firm, or product names is for descriptive purposes only and does not imply endorsement by the U.S. Government.

Although this information product, for the most part, is in the public domain, it also may contain copyrighted materials as noted in the text. Permission to reproduce copyrighted items must be secured from the copyright owner.

Suggested citation:

U.S. Geological Survey and Mexican National Commission for the Knowledge and Use of Biodiversity, 2021, The North American Breeding Bird Survey in Mexico, 2008 to 2018-A Status Report: U.S. Geological Survey Circular 1479, 33 p., https://doi.org/10.3133/cir1479.

Associated data for this publication:

U.S. Geological Survey and Mexican National Commission for the Knowledge and Use of Biodiversity, 2021, The North American Breeding Bird Survey in Mexico, 2008-2018-unprocessed data: U.S. Geological Survey data release, https://www.doi.org/10.5066/P9L4KBDC.

ISSN 2330-5703 (online) 


\section{Contents}

Abstract

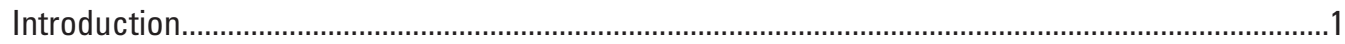

History and Current Scope of the Breeding Bird Survey in the United States and Canada ....1

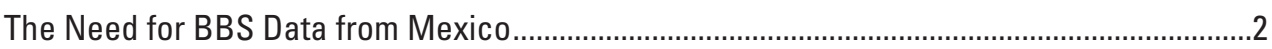

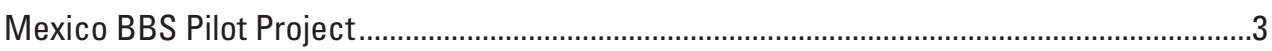

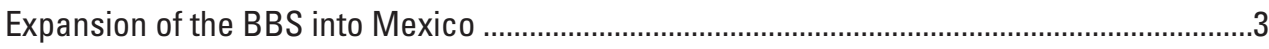

Mexican BBS: The First 11 Years, 2008-18

Route Locations and Coverage .............................................................................................

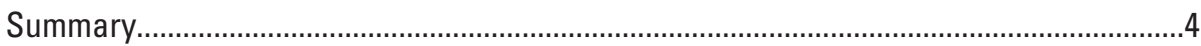

Routes Surveyed: Overall and by State .......................................................................

Routes Surveyed, by Bird Conservation Region ................................................................

Routes Surveyed, by State/BCR Strata .........................................................................

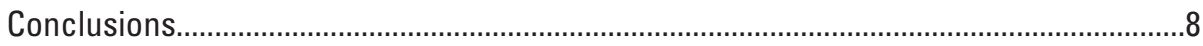

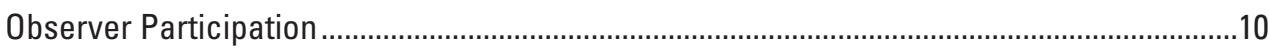

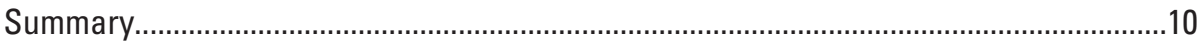

Number of Observers and Turnover .........................................................................10

Identification Skills, Training, and Resources................................................................10

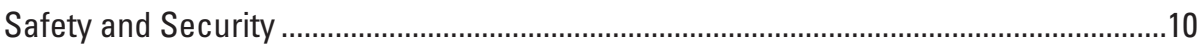

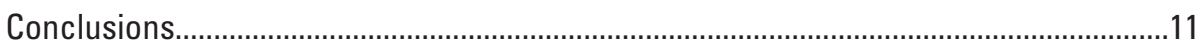

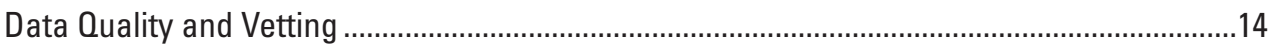

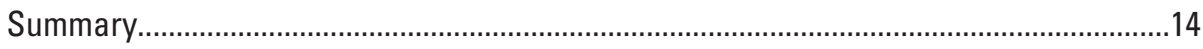

The Need for Screening Count Data ...........................................................................14

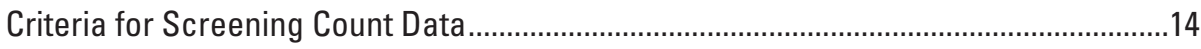

Number of Comparable Surveys ................................................................................

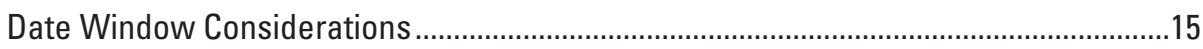

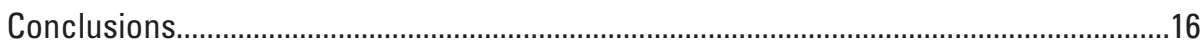

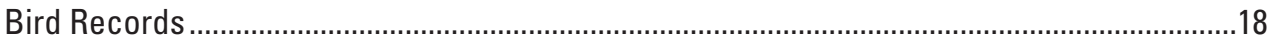

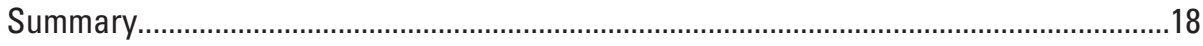

Quality-Control Criteria Used to Evaluate Species Data ..................................................18

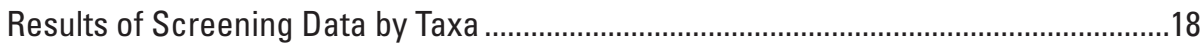

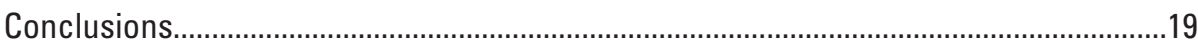

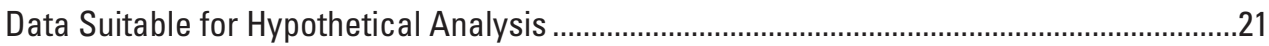

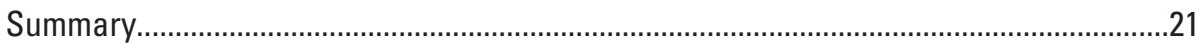

Sample Size Requirements .................................................................................21

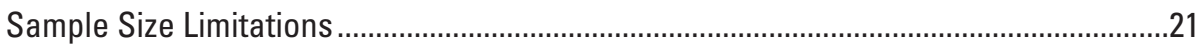

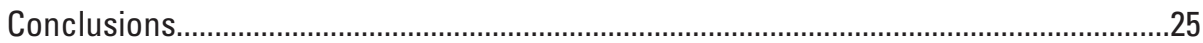

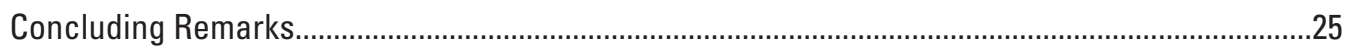

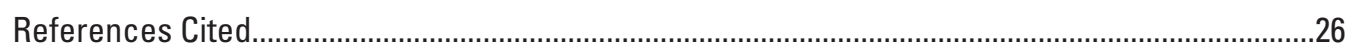

Appendix 1. Summary of the Data Used in This Report ..............................................................30 


\section{Figures}

1. Graph showing the number of years each of 68 Breeding Bird Survey routes in Mexico was surveyed during 2008-18 and a summary of the total number of routes surveyed one or multiple years...

2. Map showing the starting locations for the 68 Breeding Bird Survey routes in northern Mexico that were surveyed at least once during 2008-18....

3. Map showing the 15 Bird Conservation Regions in the seven-State Mexican focal area

4. Graph showing the average monthly rainfall during 2008-18 for each State in the Mexican Breeding Bird Survey focal area.

\section{Tables}

1. The number of Breeding Bird Survey routes surveyed in northern Mexico during the 11-year period, 2008-18.

2. Twenty-eight State/BCR strata occurring in the Mexican Breeding Bird Survey seven-State focal area.

3. Tallies of the number of Breeding Bird Surveys conducted by 31 observers, by each Mexican State and by year, during 2008-18

4 The number of Mexican Breeding Bird Surveys that meet each quality control criterion

5. List of 42 species commonly reported on Mexican Breeding Bird Survey routes

6. Data from Breeding Bird Survey Routes in Mexico that would meet the absolute minimum requirement for inclusion in trend analyses according to methods typically used by the U.S. Geological Survey for United States/Canada Breeding Bird Survey analyses

\section{Abbreviations}

$\begin{array}{ll}\text { BBS } & \text { Breeding Bird Survey } \\ \text { BCR } & \text { Bird Conservation Region } \\ \text { CONABIO } & \text { Comisión Nacional para el Conocimiento y Uso de la Biodiversidad } \\ \text { CWS } & \text { Canadian Wildlife Service } \\ \text { FWS } & \text { U.S. Fish and Wildlife Service } \\ \text { NABCI } & \text { North American Bird Conservation Initiative } \\ \text { USGS } & \text { U.S. Geological Survey }\end{array}$




\section{Acknowledgments}

We gratefully acknowledge the efforts of the numerous North American Breeding Bird Survey (BBS) volunteers who contributed their time and expertise to collect bird data in Mexico. We also thank the many people who contributed to the design, establishment, and support of the BBS program expansion, including but not limited to, Carol Beardmore, Humberto Berlanga García, Jang Byun, Connie Downes, Charles Francis, Mario Guerrero, Mary Gustafson, Eduardo Inigo-Elias, Michael Lutmerding, Daniel Murry, Bruce Peterjohn, Tiffanie Powell, René Valdes, Diana Venegas, and David Ziolkowski, Jr.

The U.S. Fish and Wildlife Service (FWS), Sonoran Joint Venture, Rio Grande Joint Venture, Comisión Nacional de Áreas Naturales Protegidas, la Dirección General de Vida Silvestre, Pronatura A.C., Canadian Wildlife Service, U.S. Geological Survey (USGS), and the Comisión Nacional para el Conocimiento y Uso de la Biodiversidad (CONABIO) provided support for the BBS expansion into Mexico, with funding provided for various aspects by the FWS North American Migratory Bird Conservation Act, CONABIO, and the USGS Ecosystems Mission Area.

Daniel K. Niven (Aperture Federal) prepared this report under the direction of Keith L. Pardieck (USGS) and Vicente Rodríguez-Contreras (CONABIO). We gratefully acknowledge the invaluable input on earlier drafts of this report from our USGS colleagues, Shannon Beliew, Michael Lutmerding, and David Ziolkowski, Jr. We also thank Antonio Celis-Murillo, Sam Droege, Joseph Battista, Ruth Larkins (retired) and Robin White for their reviews of the final document as well as Jeff Corbett, USGS Reston Publishing Service Center, for providing layout and design services. The USGS funded publication of this circular.

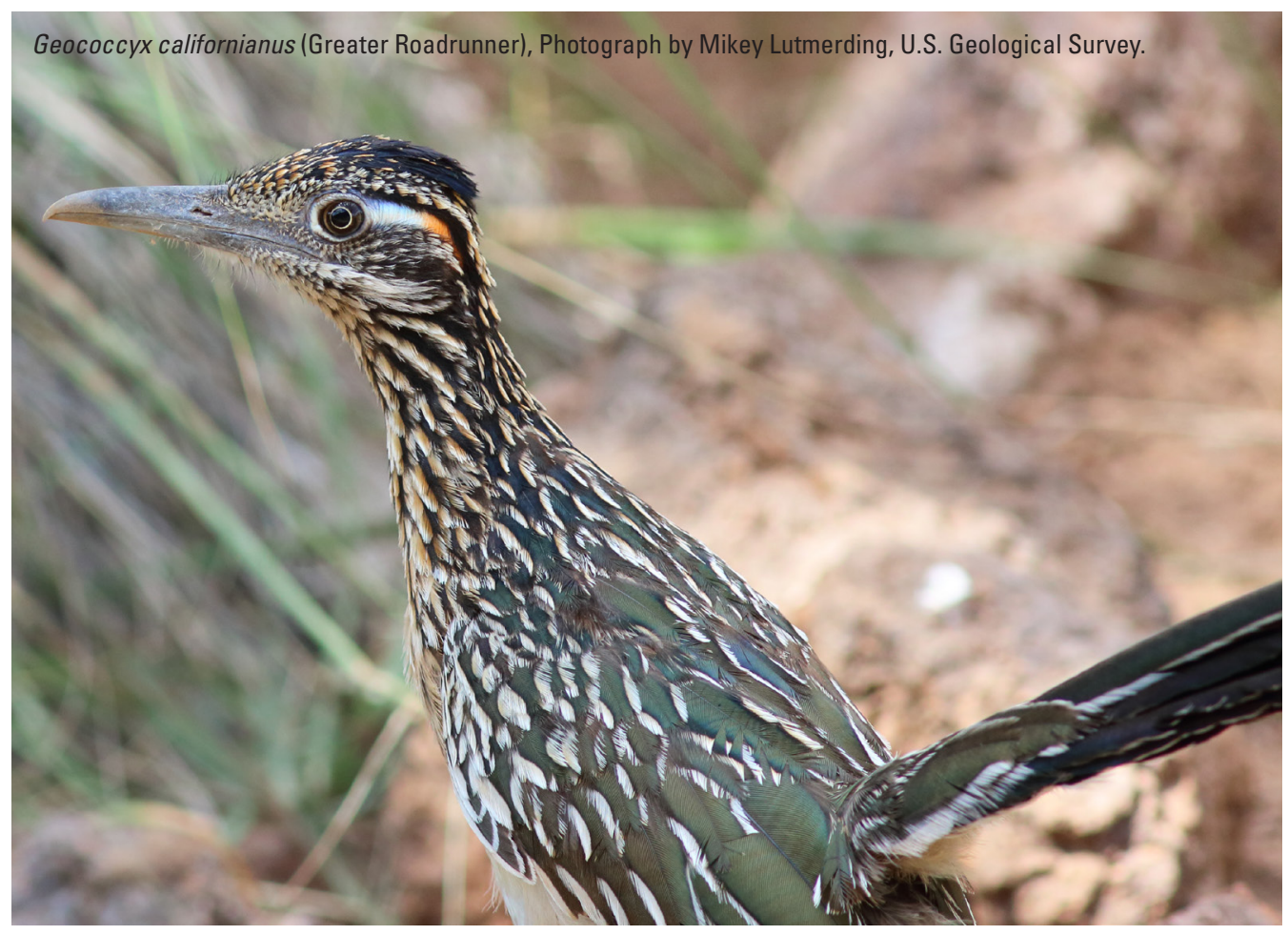





\title{
The North American Breeding Bird Survey in Mexico, 2008 to 2018-A Status Report
}

\author{
By U.S. Geological Survey and Mexican National Commission for the Knowledge and Use of Biodiversity
}

\section{Abstract}

Collection of avian population data has repeatedly been identified as a high priority for bird conservation in Mexico. To meet this need, in 2008 the North American Breeding Bird Survey (BBS), a volunteer-based survey, was expanded to include northern Mexico. The BBS in Mexico (Mexican BBS) is managed by the North American Bird Conservation Initiative (NABCI), Mexico's National Coordination Office inside the Comisión Nacional para el Conocimiento y Uso de la Biodiversidad (CONABIO).

During 2008-18, 252 surveys were conducted along 68 routes in Mexico, with geographic coverage varying from year to year. Of these 68 routes, 36 were surveyed three or more times. Thirty-one observers conducted the surveys, and 21 of these observers conducted two or more surveys. Just two observers conducted more than one-third of the 252 surveys, and both observers were paid to conduct the surveys. The low availability of local observers who are qualified, willing, and able to volunteer their services to conduct BBS surveys may prove to be the biggest obstacle to the success of the Mexican BBS program, especially in the context of Mexico's ongoing safety and security concerns.

Apart from the amount of data collected, many surveys did not adhere to pre-established quality-control requirements, and this would result in the exclusion of a large percentage of the data from potential trend analyses. Only 31 percent of the surveys met all the quality-control criteria. Additional observer training may help resolve this issue. Of greater concern is the selection of region-specific sampling date windows during which the surveys are conducted. Observers consistently conducted surveys outside the preliminarily prescribed sampling date window, reflecting the need to re-evaluate the regional appropriateness of this date window.

Regardless of the quality of the data, the quantity of data available from 2008 to 2018 is insufficient for trend analysis using methods typically employed by U.S. Geological Survey BBS analysts. Reaching minimum sample size thresholds for statistical analysis will require a substantial increase in effort. During 2008-18, no strata (defined as the intersection of State and Bird Conservation
Region boundaries) reached the suggested minimum of 14 sampled routes, and most routes were not run consistently.

This report provides information needed for an evaluation of the merits of continuing to invest in the Mexican BBS program in its current form. Such an evaluation should consider the likelihood of achieving the primary project goal of producing reliable long-term population trend estimates, a projected timeline for meeting this goal, and include an assessment of the potential value of any additional data products.

\section{Introduction}

The purpose of this report is to provide an overview and summary of the North American Breeding Bird Survey (BBS) in northern Mexico (Mexican BBS) through 2018. The report includes a brief synopsis of the program's origins; an overview of the data available at the time the report was completed; and a discussion of some of the program's limitations, including discussion of some of the challenges of successfully implementing the program. The intent here is to neither provide specific recommendations for improving the implementation of the program nor recommend whether continuation of the program is merited. Rather, the aim is to provide a non-biased summary of the status of the program to inform ongoing discussions by the managing agencies and the conservation community regarding these programmatic issues.

\section{History and Current Scope of the Breeding Bird Survey in the United States and Canada}

The North American BBS began in 1966 in the eastern United States and the Atlantic region of Canada (Robbins and others, 1986). It expanded quickly to include the western United States and parts of Alaska and southwest Canada (Sauer and others, 2013). The annual sample size has continued to grow and currently includes approximately 3,300 surveys per year (Pardieck and others, 2019).

Success at implementing the program may be attributed in part to the simplicity of the field protocols, which can be conducted by anyone who has sufficient bird identification 
skills, good hearing, and access to transportation. Standard BBS field protocols dictate that each roadside survey is conducted once per year on a route consisting of 50 point counts, approximately 0.5 mile ( 0.8 kilometer) apart.

Surveys are conducted during the breeding season, starting 0.5 hour before sunrise. At each location, a citizen scientist or professional biologist highly skilled in avian identification conducts a 3-minute point count. The observer stands near his or her vehicle and records the total number of each bird species seen within 400 meters of the stop location or heard during the 3-minute period without the aid of any method of attraction. Data also are collected on factors that may affect avian counts, such as time and weather conditions at the beginning and end of the survey. Detailed instructions can be found at https://www.pwrc.usgs.gov/bbs/participate/ instructions.html.

As a result of the broad spatial and temporal scope of the survey, as well as the availability of comprehensive U.S. Geological Survey (USGS) and Canadian Wildlife Service (CWS) analyses, the BBS may now be regarded as the premier source of information for bird population status and change throughout North America (Sauer and others, 2017c). The analyzed results are widely used in peer-reviewed studies and for myriad scientific and conservation-planning purposes (Pardieck and Ziolkowski, 2009). For example, BBS results are a primary source of information for population trend scores used in species assessment (Rosenberg and others, 2017) and for State of the Birds reports (for example, North American Bird Conservation Initiative, 2016).

Approximately 700 species are routinely detected by the BBS, and population trend estimates have traditionally been generated for a core group of about 425 of these species (Sauer and others, 2017a,c). Many of the excluded species are rare, local, nocturnal, and (or) occur predominantly north or south of the core BBS sampling area. A recent revision of trend analysis methods, however, has allowed for the inclusion of an additional 122 species in the analyses (Sauer and others, 2017b); 44 of these were defined as "southern" species (those with greater than 50 percent of their breeding range located south of the United States and Mexico border). Based on sample size, abundance, and precision estimates, only 4 of these 44 "southern" species were classified as "reasonably monitored" whereas 17 were classified as "poorly monitored" (Sauer and others, 2017b). Moreover, 7 of these 44 "southern" species are of conservation concern (Rosenberg and others, 2016) but none of these 7 species were "reasonably monitored." This highlights a consequence of restricting BBS coverage to the United States and Canada; many of the "southern" species surveyed by the BBS have geographic distributions that extend well into Mexico, but the absence of monitoring data from Mexico has limited the ability to assess the overall population status and trends of these species.

\section{The Need for BBS Data from Mexico}

Obtaining trend information for birds in Mexico has often been identified as a high priority research need (CIPAMEX, 2003; Dunn and others, 2005; Santana, 2005; Berlanga and others, 2010), and expansion of the BBS into Mexico has been suggested as a logical method for obtaining these trend data (Peterjohn, 1994; Dunn and others, 2005). A long list of stakeholders, including Comisión Nacional para el Conocimiento y Uso de la Biodiversidad (CONABIO), the U.S. Fish and Wildlife Service (FWS), and other partners in the North American Bird Conservation Initiative (NABCI) could benefit from the existence of a Mexican BBS. For example, six NABCI Bird Conservation Regions (BCRs; 32, $33,34,35,36,37)$ cross the United States-Mexican border, and three Migratory Bird Joint Ventures (U.S. Fish and Wildlife Service, 2021) conduct conservation work in these BCRs (Sonoran, Rio Grande, and Gulf Coast Joint Ventures; Rosenberg and others, 2016). These stakeholders could benefit from the implementation of data collection methods in Mexico that produce population data that can be easily integrated into analyses with similar United States data.

In addition to the need for more information about species that breed across Mexico, the United States, and Canada, the Mexican government and conservation planners also could benefit from information concerning bird populations that occur predominantly in Mexico and possibly farther south. The paucity of information regarding the distribution, abundance, and trends of birds in Mexico has made it difficult to produce reliable conservation status assessments. Consequently, the need for this information ranked high at a 1998 workshop aimed at identifying Mexican bird conservation issues (CIPAMEX, 2003). That need was reiterated by Santana (2005) who concludes that a research agenda for Mexico should include research on the status, trends, and natural dynamics of Mexican bird populations. For example, the Partners in Flight Population Trend (PT) scores that are widely used in bird conservation planning (for example, Rich and others, 2004; Rosenberg and others, 2016; North American Bird Conservation Initiative, 2016) are based on BBS data from the United States and Canada (Dunn and others, 2005; Panjabi and others, 2017; Rosenberg and others, 2017), but no similar data are available for generating the PT scores used for birds in Mexico. Bird conservation planning in Mexico could benefit from having PT scores informed by and (or) derived from data collected in Mexico using comparable BBS protocols. At a broader scale, all three countries could benefit from having access to a more complete continental assessment of avian distributions and trends. 


\section{Mexico BBS Pilot Project}

From 1993 to 1995 a pilot project was undertaken to evaluate the feasibility of expanding the BBS into Mexico (Rodríguez-Contreras and others, 2014). Volunteer field observers, most of which were from the United States, conducted BBS surveys in portions of northern Mexico over three seasons (Bruce Peterjohn, USGS, oral commun., 2019). [Volunteer observers from the United States were used for this feasibility study, as opposed to observers from Mexico, because they were already trained and experienced BBS observers.] Eighty-seven surveys were conducted along 48 routes in five Mexican border States (Sonora, Chihuahua, Coahuila, Nuevo León and Tamaulipas). These routes were predominantly non-random with respect to location. A total of 212 species were reported. Although relative abundance data were collected, the primary intent of this project was not to produce population trends, but rather to assess the logistics of collecting such data. For example, would BBS observers discover that the road systems in northern Mexico were of sufficient quality to reasonably expect that 50 -stop routes could be sampled within the BBS's morning time window? The overarching conclusion from the pilot project was that a permanent expansion of the BBS into northern Mexico was logistically feasible (Peterjohn, 1994). Using the project's results, Dunn and others (2005) estimated that a BBS-style program in northern Mexico could eventually provide adequate population trend estimates for more than 80 bird species (an underestimate because the analysis covered only landbirds that regularly breed in the United States and Canada). The pilot data, however, were too sparse to produce long-term trend estimates. Moreover, the pilot data had been collected from largely non-randomly located routes; therefore, the data were not incorporated into survey-wide analyses (Peterjohn and others, 1996; Pardieck and Sauer, 2000).

Although the logistics of expanding the BBS were deemed feasible, it was recognized that the success of a permanent expansion would hinge on finding skilled field observers in Mexico who could commit to participating on an ongoing, multi-year basis (Bruce Peterjohn, USGS, oral commun., 2019). This task was further complicated by the challenge of recruiting observers willing to conduct surveys in potentially insecure field locations. [This issue is discussed below in the section dealing with "Observer Participation".] It was anticipated that there would be challenges at the institutional level regarding financial and logistic support (for example, the capacity to hire coordinators who would dedicate time to project management, quality control, training, and support of stakeholders) and the availability of computer/ software resources for data management and support. It was evident that a long-term commitment would be required from the Mexican government at the outset to ensure that the project remained well supported for its formative years. This would allow the effort to accrue enough meaningful data to, in turn, produce a suite of data products that could be used to demonstrate value and secure long-term financial support.

\section{Expansion of the BBS into Mexico}

In April 1999, the USGS Eastern Ecological Science Center (formerly the Patuxent Wildlife Research Center) convened a Peer Review Panel to review the scientific and operational aspects of the U.S. BBS program (O'Connor and others, 2000). Based in part on the results from the Mexican pilot study, one suggestion of the panel was to expand the BBS into northern Mexico. It was concluded, however, that institutional and ornithological support within Mexico was insufficient at the time to maintain a long-term commitment to the program.

Another BBS workshop was held in 2005 to review the program's progress since 1999 and to assist in the development of a 5-year strategic plan for the BBS. At that time, it was recognized that the Mexican avian conservation community had grown, as had the need for better avian population trend information. The Comisión Nacional para el Conocimiento y Uso de la Biodiversidad (CONABIO) committed to the development of a Mexican BBS program in partnership with the USGS and CWS. Their intent was to address avian population information needs in Mexico and to provide information to improve continental avian trend estimates (Pardieck, 2008). Consequently, an objective was included in the strategic plan to expand the BBS into Mexico by 2010 (U.S. Geological Survey, 2007).

The relevant action items identified in the strategic plan included (1) conduct a workshop at the North American Ornithological Conference in Veracruz, Mexico (October 2006), aimed at discussing approaches for implementing the program and at establishing a working group to develop and implement a strategy, (2) translate existing BBS materials into Spanish, and (3) develop strategies specific to participant training and recruitment in Mexico (U.S. Geological Survey, 2007). Initial funding was obtained through a FWS grant, using volunteer contributions from U.S. BBS observers as a match. These funds were used to kick off the program's expansion, with the bulk of the funds going to CONABIO to finance their efforts in Mexico. Additional funds were provided by the USGS for the Sonoran Joint Venture and Rio Grande Joint Venture to hire two regional coordinators for 1 year. These coordinators were contracted to work full-time with CONABIO to increase the number of BBS routes surveyed. After their initial contracts ended, CONABIO then hired them part time to continue the work (Vincente Rodríguez-Contreras, CONABIO, oral commun., 2020).

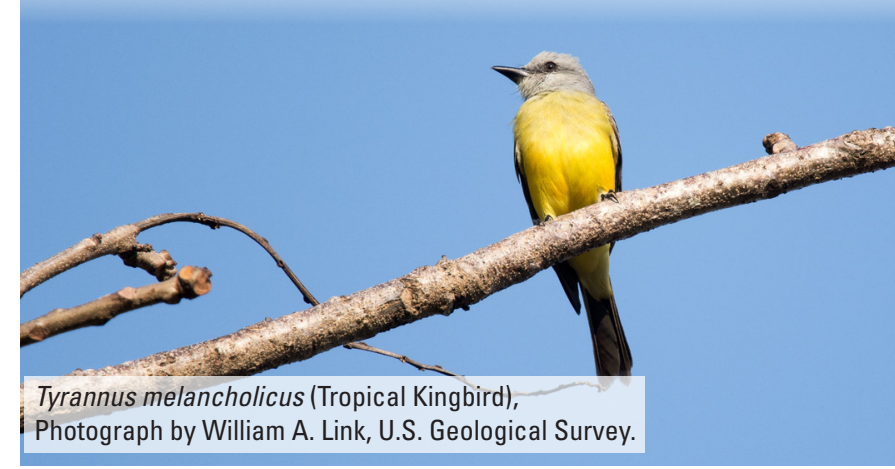




\section{Mexican BBS: The First 11 Years, 2008-18}

In this report, we evaluate all Mexican BBS data collected from 2008 to 2018 that were submitted to the BBS database as of September 11, 2018. These data are stored in the BBS database, housed at the USGS Eastern Ecological Science Center in Laurel, Maryland, in the same manner as data collected from the United States and Canada (Pardieck and others, 2019). Whereas all United States and Canadian BBS data are regularly subjected to a rigorous review process before they are released to the public (Pardieck and others, 2019), a similar review and editing process has not yet been developed for the Mexican BBS. Therefore, the data have not been subjected to a rigorous end-of-year review and editing process, and consequently these data are considered provisional and have not been made publicly available until now. They are presented here solely for the purpose of evaluating the program and are not intended to be used "as is" for population analyses, either on their own or in aggregate with United States and Canadian BBS data.

The data are stored in a series of tables that include route details (route names and codes, country, state, BCR, starting point coordinates, and pre-determined required start times), route run data (information about each run of a route, including survey date, observer, start/end times, weather conditions, and information about the protocols used), and species data (records for all taxa recorded on each run of a route, including species name, species identification number, and count totals from each of 50 route stops). The Mexican BBS data in each of these tables were evaluated for this report, covering the period 2008-18, and copies of these data tables are available as a companion USGS data release (United States Geological Survey and Mexican National Commission for the Knowledge and Use of Biodiversity, 2021). The information evaluated in this report are grouped by Route Locations and Coverage, Observer Participation, Data Quality and Vetting, Bird Records, and Data Suitable for Hypothetical Analysis.

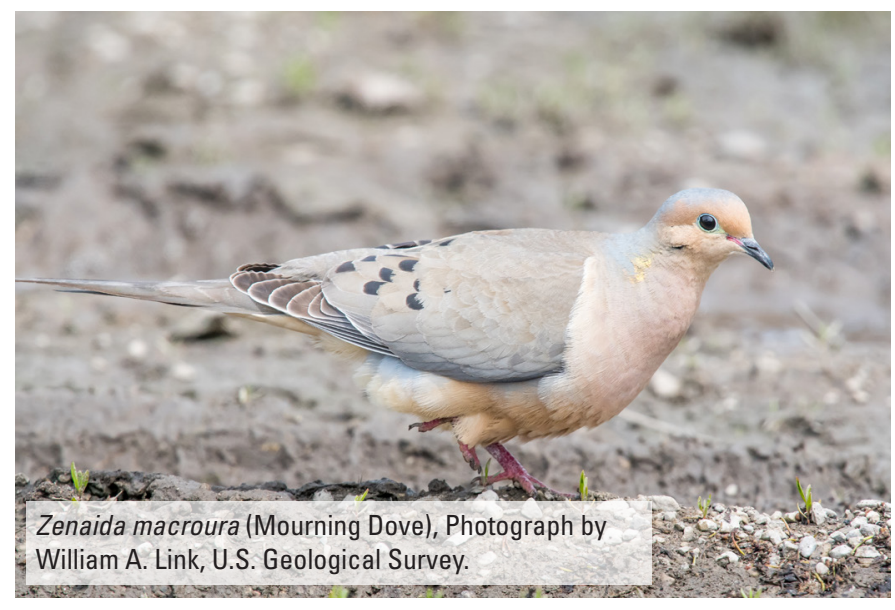

\section{Route Locations and Coverage}

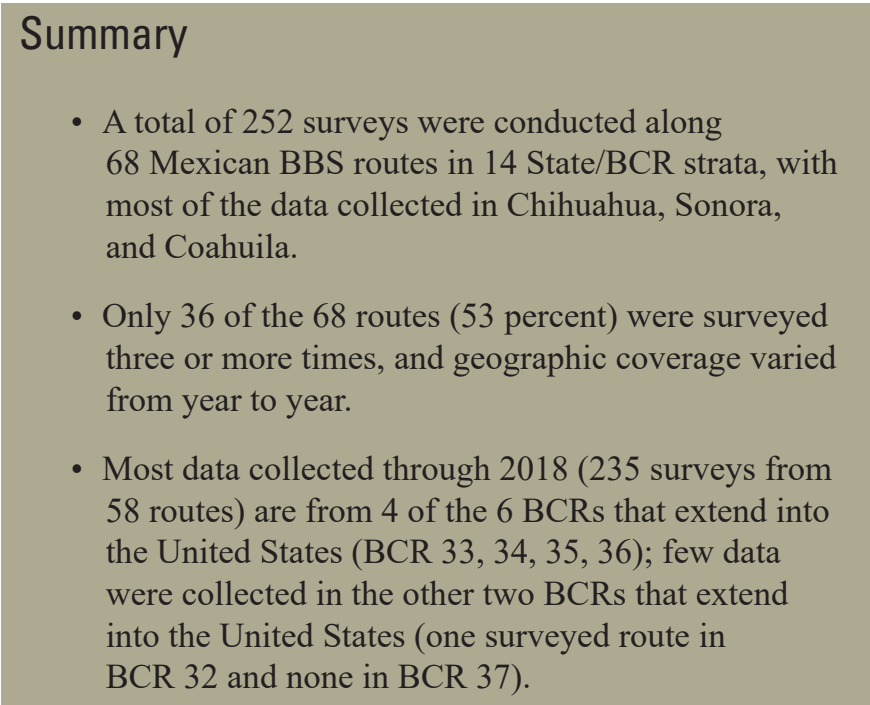

\section{Routes Surveyed: Overall and by State}

In total, 252 surveys were conducted along 68 routes in a seven-State focal area composed of six Mexican States along the United States border and Baja California Sur (table 1). The greatest number of surveys were conducted in Chihuahua (96 surveys; 23 routes), followed by Sonora (57 surveys; 10 routes) and Coahuila (49 surveys; 16 routes). Sample sizes were smallest in Baja California Sur (four routes surveyed; each only once) and Tamaulipas (two routes surveyed; one twice and one three times) (table 1, table 1.1). The number of surveys conducted each year increased from 2 in 2008 (one each in Baja California and Sonora) to a maximum of 44 surveys in 2015 (table 1). The number of routes surveyed dropped to 16 in 2016 but increased each year since. The routes surveyed varied among years. In 2009 and 2010, 17 of 18 surveys were conducted in Chihuahua. Surveys began to be conducted in the eastern States of Mexico in 2012, and 2014 marked the only year that at least one route was surveyed in all seven States (table 1).

There was low continuity among the individual routes run from year to year. For example, among the 68 routes surveyed, nearly one-half were surveyed only once or twice (32 routes, 47 percent), and only 21 routes were surveyed five or more times (fig. 1). Moreover, only four States (Sonora, Chihuahua, Coahuila, Nuevo León) included one or more routes that were surveyed at least five times (fig. 2, table 1.1). 
Table 1. The number of Breeding Bird Survey routes surveyed in northern Mexico during the 11-year period, 2008-18. Data are summarized by State and Bird Conservation Region.

[BCR, Bird Conservation Region; no., number]

\begin{tabular}{|c|c|c|c|c|c|c|c|c|c|c|c|c|c|}
\hline & \multicolumn{11}{|c|}{ Number of routes surveyed in: } & \multirow{2}{*}{$\begin{array}{c}\text { Total } \\
\text { no. of } \\
\text { surveys }\end{array}$} & \multirow{2}{*}{$\begin{array}{l}\text { Total } \\
\text { no. of } \\
\text { routes }\end{array}$} \\
\hline & 2008 & 2009 & 2010 & 2011 & 2012 & 2013 & 2014 & 2015 & 2016 & 2017 & 2018 & & \\
\hline \multicolumn{14}{|c|}{ State $^{1}$} \\
\hline $\mathrm{BCS}$ & 0 & 0 & 0 & 1 & 0 & 0 & 1 & 2 & 0 & 0 & 0 & 4 & 4 \\
\hline $\mathrm{BCN}$ & 1 & 0 & 0 & 2 & 2 & 2 & 2 & 2 & 2 & 3 & 3 & 19 & 3 \\
\hline SON & 1 & 0 & 1 & 6 & 6 & 6 & 7 & 8 & 7 & 7 & 8 & 57 & 10 \\
\hline $\mathrm{CHH}$ & 0 & 7 & 10 & 8 & 12 & 11 & 12 & 14 & 5 & 6 & 11 & 96 & 23 \\
\hline $\mathrm{COA}$ & 0 & 0 & 0 & 0 & 0 & 7 & 9 & 14 & 2 & 8 & 9 & 49 & 16 \\
\hline NLE & 0 & 0 & 0 & 0 & 3 & 4 & 5 & 4 & 0 & 3 & 3 & 22 & 10 \\
\hline TAM & 0 & 0 & 0 & 0 & 0 & 2 & 2 & 0 & 0 & 0 & 1 & 5 & 2 \\
\hline Total: & 2 & 7 & 11 & 17 & 23 & 32 & 38 & 44 & 16 & 27 & 35 & 252 & 68 \\
\hline \multicolumn{14}{|c|}{ Bird Conservation Region² } \\
\hline $\mathrm{BCR} 32^{3}$ & 1 & 0 & 0 & 0 & 0 & 0 & 0 & 0 & 0 & 1 & 1 & 3 & 1 \\
\hline BCR $33^{3}$ & 1 & 0 & 1 & 8 & 8 & 8 & 9 & 10 & 9 & 9 & 9 & 72 & 11 \\
\hline BCR $34^{3}$ & 0 & 4 & 7 & 3 & 5 & 3 & 3 & 3 & 1 & 1 & 2 & 32 & 11 \\
\hline BCR $35^{3}$ & 0 & 3 & 3 & 5 & 9 & 14 & 19 & 24 & 5 & 12 & 17 & 111 & 29 \\
\hline BCR $36^{3}$ & 0 & 0 & 0 & 0 & 0 & 3 & 2 & 3 & 1 & 4 & 4 & 17 & 6 \\
\hline $\mathrm{BCR} 37^{3}$ & 0 & 0 & 0 & 0 & 0 & 0 & 0 & 0 & 0 & 0 & 0 & 0 & 0 \\
\hline BCR 39 & 0 & 0 & 0 & 0 & 0 & 0 & 0 & 0 & 0 & 0 & 0 & 0 & 0 \\
\hline BCR 40 & 0 & 0 & 0 & 1 & 0 & 0 & 0 & 2 & 0 & 0 & 0 & 3 & 3 \\
\hline BCR 41 & 0 & 0 & 0 & 0 & 0 & 0 & 0 & 0 & 0 & 0 & 0 & 0 & 0 \\
\hline BCR 42 & 0 & 0 & 0 & 0 & 0 & 0 & 1 & 0 & 0 & 0 & 0 & 1 & 1 \\
\hline BCR 43 & 0 & 0 & 0 & 0 & 0 & 0 & 0 & 0 & 0 & 0 & 1 & 1 & 1 \\
\hline BCR 48 & 0 & 0 & 0 & 0 & 1 & 4 & 4 & 2 & 0 & 0 & 1 & 12 & 5 \\
\hline BCR 49 & 0 & 0 & 0 & 0 & 0 & 0 & 0 & 0 & 0 & 0 & 0 & 0 & 0 \\
\hline BCR 52 & 0 & 0 & 0 & 0 & 0 & 0 & 0 & 0 & 0 & 0 & 0 & 0 & 0 \\
\hline BCR 63 & 0 & 0 & 0 & 0 & 0 & 0 & 0 & 0 & 0 & 0 & 0 & 0 & 0 \\
\hline Total: & 2 & 7 & 11 & 17 & 23 & 32 & 38 & 44 & 16 & 27 & 35 & 252 & 68 \\
\hline
\end{tabular}

${ }^{1}$ State abbreviations: BCS, Baja California Sur; BCN, Baja California; SON, Sonora; CHH, Chihuahua; COA, Coahuila; NLE, Nuevo León; TAM, Tamaulipas.

${ }^{2}$ BCRs: 32, Coastal California; 33, Sonoran and Mojave Deserts; 34, Sierra Madre Occidental; 35, Chihuahuan Desert; 36, Tamaulipan Brushlands; 37, Gulf Coastal Prairie; 39, Sierras de Baja California; 40, Desierto de Baja California; 41, Islas del Golfo de California; 42, Sierra y Planicies de El Cabo; 43, Planicie Costera, Lomeríos y Cañones de Occidente; 48, Sierra Madre Oriental; 49, Planicie Costera y Lomeríos Secos del Golfo de México; 52, Planice Costera y Lomerios Humedos del Golfo de Mexico; 63, Isla Guadalupe.

${ }^{3}$ A BCR that overlaps the United States. 

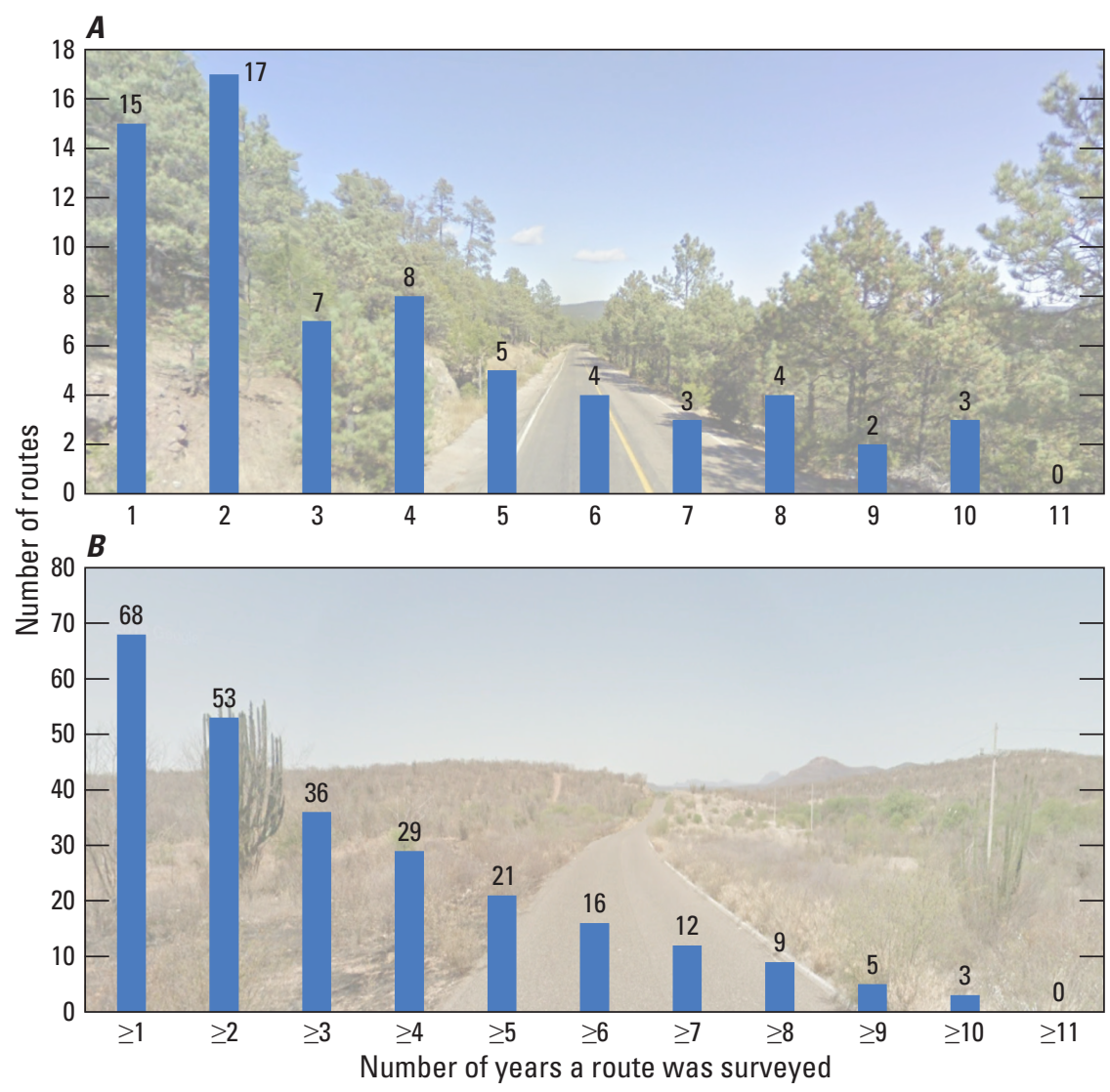

Figure 1. $A$, The number of years each of 68 Breeding Bird Survey routes in Mexico was surveyed during 2008-18 and $B$, a summary of the total number of routes surveyed one or multiple years. ( $\geq$, greater than or equal to). Photograph credits for $A$, view along the Laguna Juanota BBS route, Chihuahua. Street View image date 11/2009 (C2021 Google, and B, view along the Bachomobampo BBS route, Sonora. Street View image date 05/2015 (2021 Google.

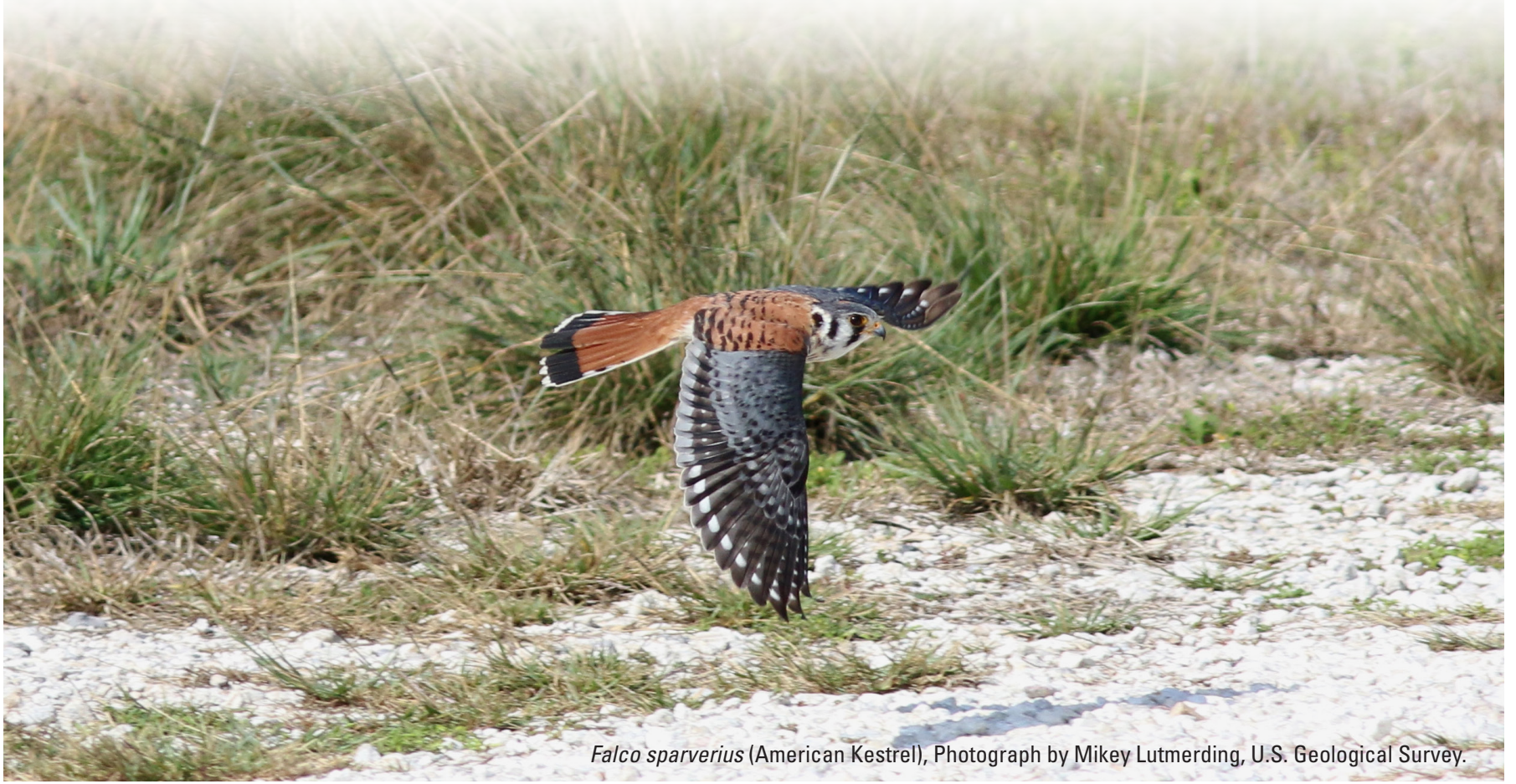




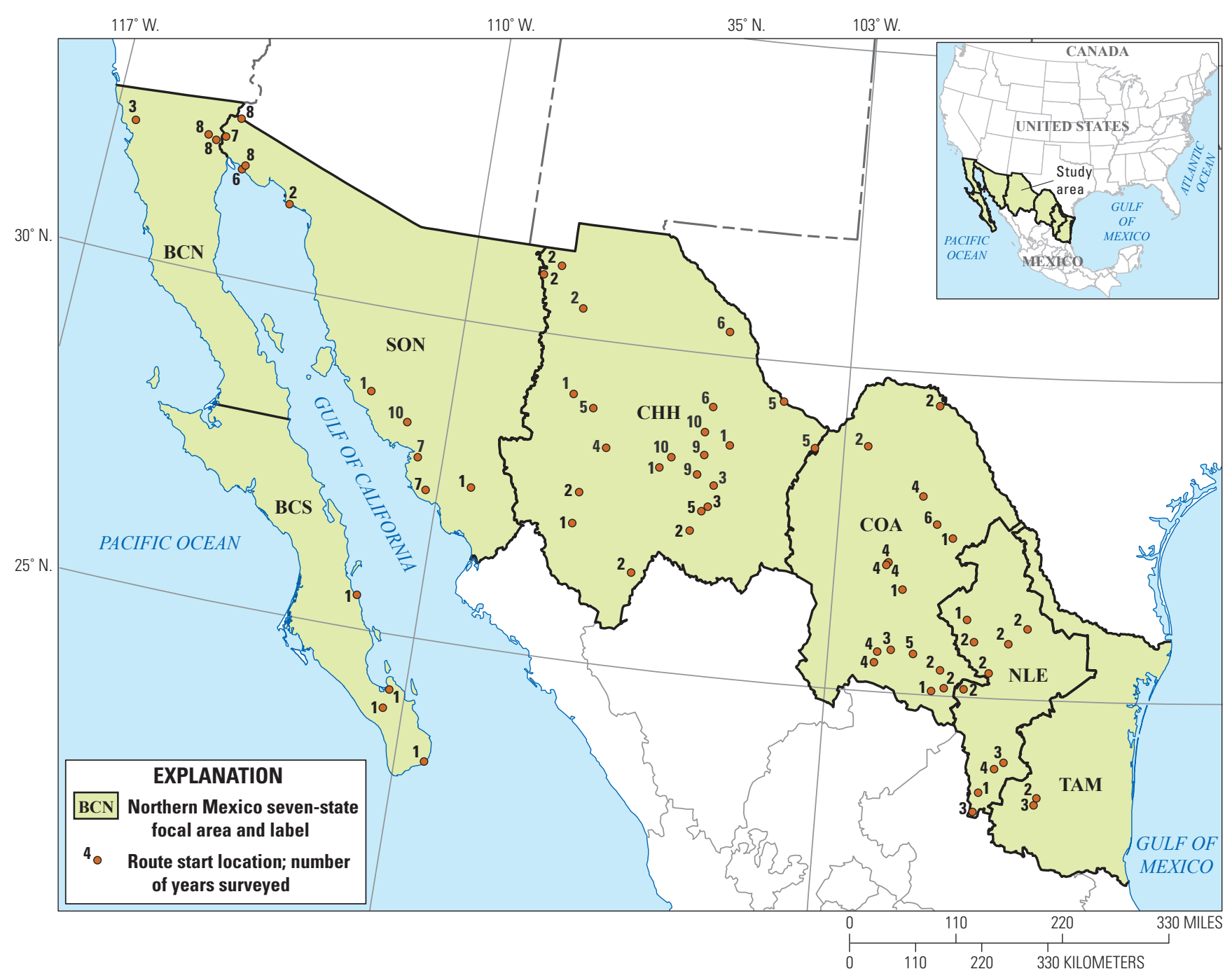

Figure 2. Starting locations for the 68 Breeding Bird Survey routes in northern Mexico that were surveyed at least once during 2008-18. State abbreviations: BCS, Baja California Sur; BCN, Baja California; SON, Sonora; CHH, Chihuahua; COA, Coahuila; NLE, Nuevo León; TAM, Tamaulipas.

\section{Routes Surveyed, by Bird Conservation Region}

Analyses of population data in relation to ecological boundaries are often more meaningful than analyses based on political boundaries. The ecological boundaries used for BBS analyses are Bird Conservation Regions (BCRs; U.S. NABCI Committee, 2000). The seven Mexican States where BBS surveys were conducted include part or all of 15 BCRs. Six of these BCRs extend into the United States, and nine are unique to Mexico (table 1, fig. 3). Among the 9 BCRs that don't lie partially within the United States, 5 are restricted to the seven-State focal area, all in the Baja region (BCRs 39, 40, 41, 42, 63); 2 of these are restricted to islands (BCRs 41 and 63).

Most of the Mexican BBS data (232 surveys from 58 routes) are from 4 of the 6 BCRs that extend into the
United States (BCR 33, 34, 35, 36, table 1). Few data, however, were collected in the two other BCRs that extend into the United States; only one route was surveyed in BCR 32 and none in BCR 37. Seventeen of the 252 surveys (from 10 routes) were conducted in four BCRs restricted to Mexico (40, 42, 43, 48); the five other Mexico-restricted BCRs received no BBS coverage (table 1), including the two islandbased BCRs, a small BCR in Baja California (BCR 39), and two Gulf Coast BCRs (49 and 52). No BBS data have been collected south of the BBS focal area.

\section{Routes Surveyed, by State/BCR Strata}

The geographic units typically used as strata for BBS analyses are formed by the intersection of States and BCRs. Appropriate subsets of State/BCR strata can be aggregated 
to produce population indexes at the scale of States, BCRs, or the entire survey area (Sauer and others, 2003; Sauer and others, 2013). There are 28 State/BCR strata in the sevenState focal area (table 2, fig. 3). The number of State/BCR strata useful for analysis would drop to 21 if small strata are excluded or aggregated with adjacent strata (the non-surveyed strata marked with an " $x$ " in table 2). One or more route was surveyed in 14 of these 21 strata, with a maximum of 12 routes surveyed one or more times in two strata. (table 2).

\section{Conclusions}

Except for a decline in participation in 2016, which was the only year funds were not available to reimburse travel expenses (Vincente Rodríguez-Contreras, CONABIO, oral commun., 2020), the number of routes surveyed each year has steadily increased. Nonetheless, the 252 surveys conducted on 68 routes during $2008-18$ were unevenly distributed among the State/BCR strata in the focal area, and few routes were consistently surveyed for multiple years.

Table 2. Twenty-eight State/BCR strata occurring in the Mexican Breeding Bird Survey seven-State focal area. One or more routes were surveyed in 14 of the 28 strata during 2008-18.

[Values indicate the number of Breeding Bird Survey routes surveyed at least once, followed by the total number of surveys conducted in the stratum during 2008-18 (in parentheses). A "- " indicates State/BCR strata that do not exist in the focal area. An " $\mathrm{x}$ " indicates small and (or) island-based strata in the focal area; these were not surveyed. BCR, Bird Conservation Region.]

\begin{tabular}{|c|c|c|c|c|c|c|c|c|c|c|c|c|c|c|c|}
\hline \multirow{2}{*}{ State $^{1}$} & \multicolumn{15}{|c|}{ Bird Conservation Region ${ }^{2}$} \\
\hline & 42 & 40 & 39 & 32 & $33^{3}$ & $34^{3}$ & $43^{3}$ & $35^{3}$ & 36 & 37 & $48^{3}$ & $49^{3}$ & $52^{3}$ & 41 & 63 \\
\hline $\mathrm{BCS}$ & $1(1)$ & $3(3)$ & - & - & - & - & - & - & - & - & - & - & - & $\mathrm{x}$ & - \\
\hline SON & - & - & - & - & $9(56)$ & 0 & $1(1)$ & & - & - & - & - & - & $\mathrm{x}$ & - \\
\hline $\mathrm{CHH}$ & - & - & - & - & - & $11(32)$ & 0 & $12(64)$ & - & - & - & - & - & - & - \\
\hline NLE & - & - & - & - & - & - & - & $5(11)$ & $2(4)$ & - & $3(7)$ & - & - & - & - \\
\hline TAM & - & - & - & - & - & - & - & 0 & 0 & 0 & $2(5)$ & 0 & $\mathrm{x}$ & - & - \\
\hline
\end{tabular}

${ }^{1}$ State abbreviations: BCS, Baja California Sur; BCN, Baja California; SON, Sonora; CHH, Chihuahua; COA, Coahuila; NLE, Nuevo León; TAM, Tamaulipas.

${ }^{2}$ BCRs: 32, Coastal California; 33, Sonoran and Mojave Deserts; 34, Sierra Madre Occidental; 35, Chihuahuan Desert; 36, Tamaulipan Brushlands; 37, Gulf Coastal Prairie; 39, Sierras de Baja California; 40, Desierto de Baja California; 41, Islas del Golfo de California; 42, Sierra y Planicies de El Cabo; 43, Planicie Costera, Lomeríos y Cañones de Occidente; 48, Sierra Madre Oriental; 49, Planicie Costera y Lomeríos Secos del Golfo de México; 52, Planice Costera y Lomerios Humedos del Golfo de Mexico; 63, Isla Guadalupe.

${ }^{3} \mathrm{~A}$ BCR that extends south of the focal area.

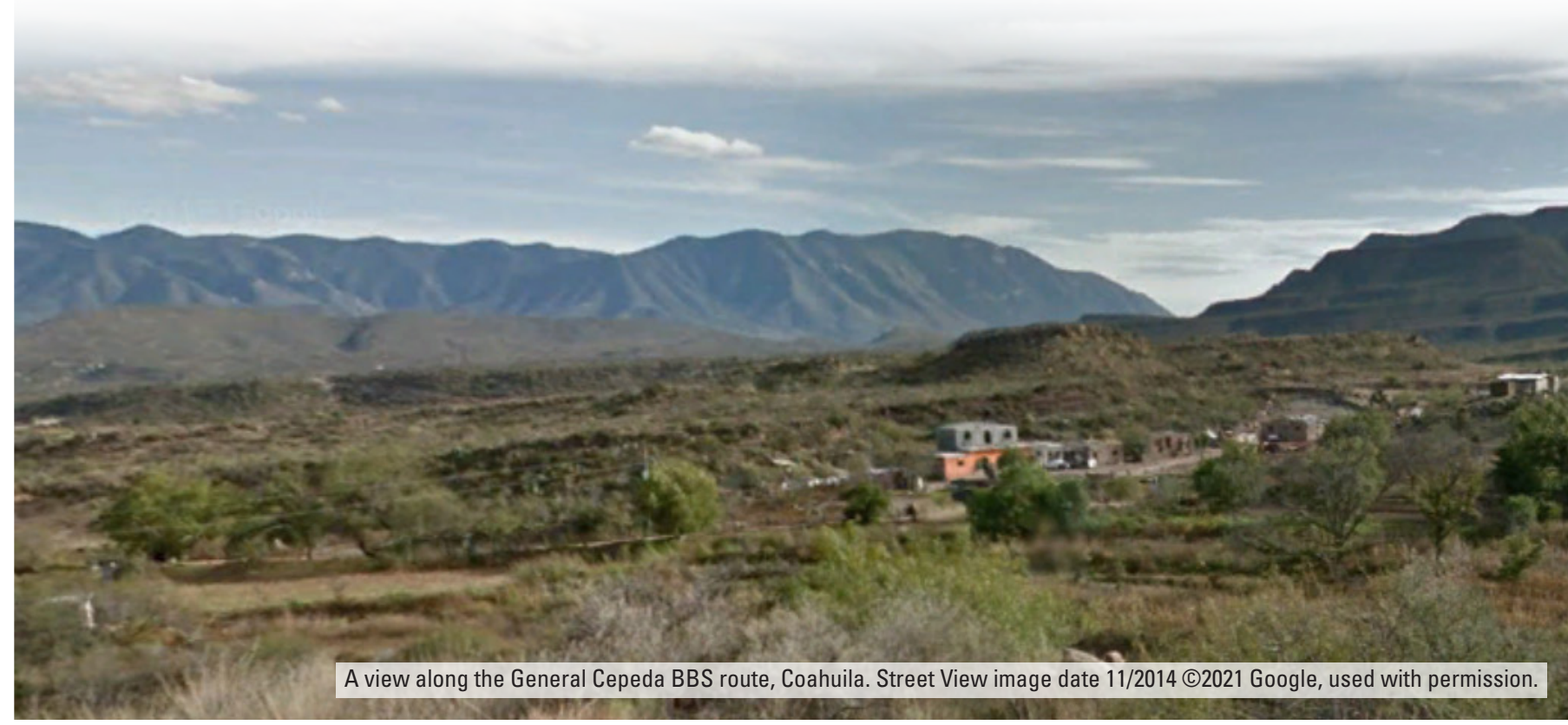




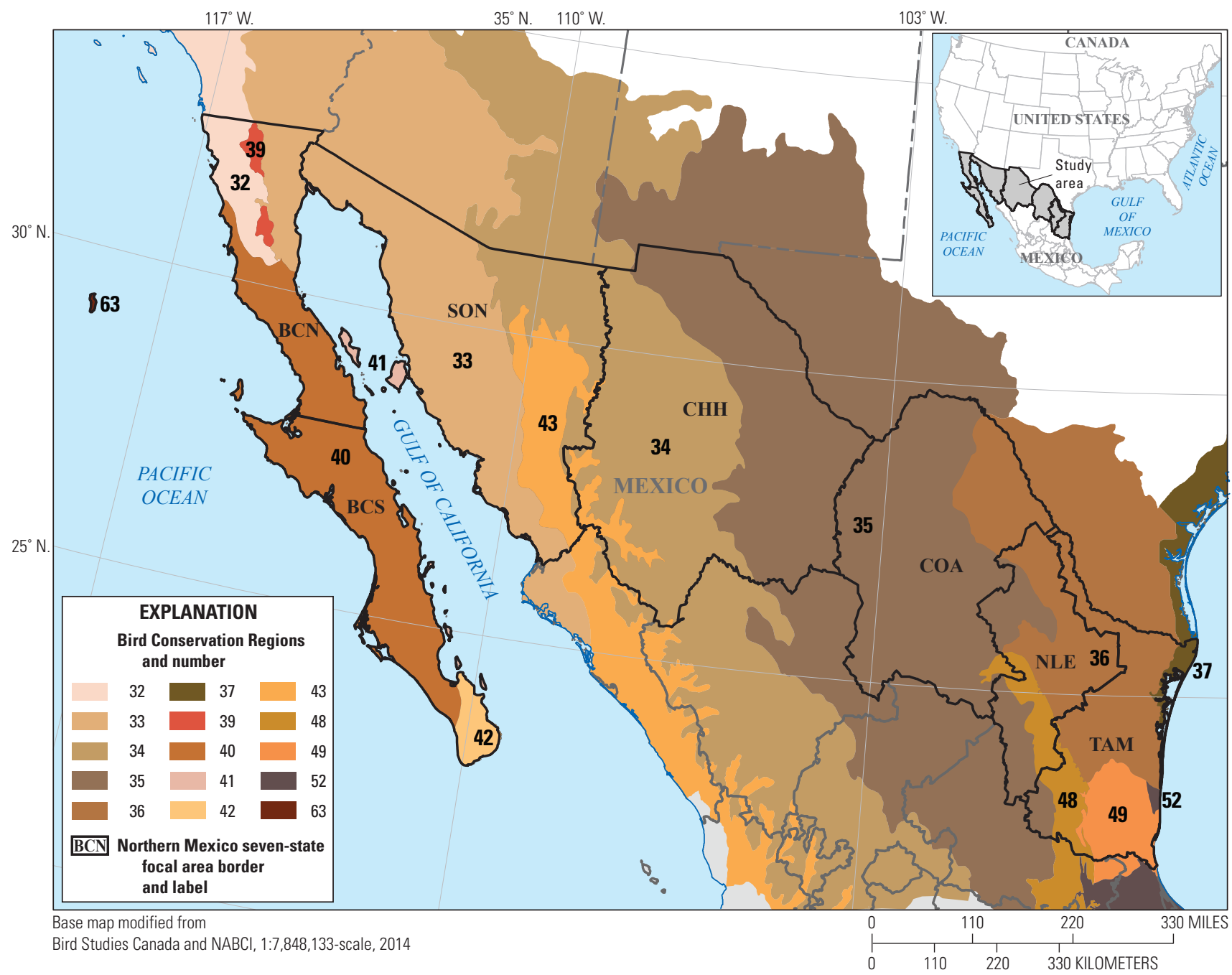

Figure 3. Map showing the 15 Bird Conservation Regions (BCRs) in the seven-State Mexican focal area. At least some Breeding Bird Survey data are available from the United States portions of all the BCRs that extend north of Mexico, but there are no data from the areas south of the focal area. Full BCR names are available in table 1. State abbreviations: BCS, Baja California Sur; BCN, Baja California; SON, Sonora; CHH, Chihuahua; COA, Coahuila; NLE, Nuevo León; TAM, Tamaulipas.

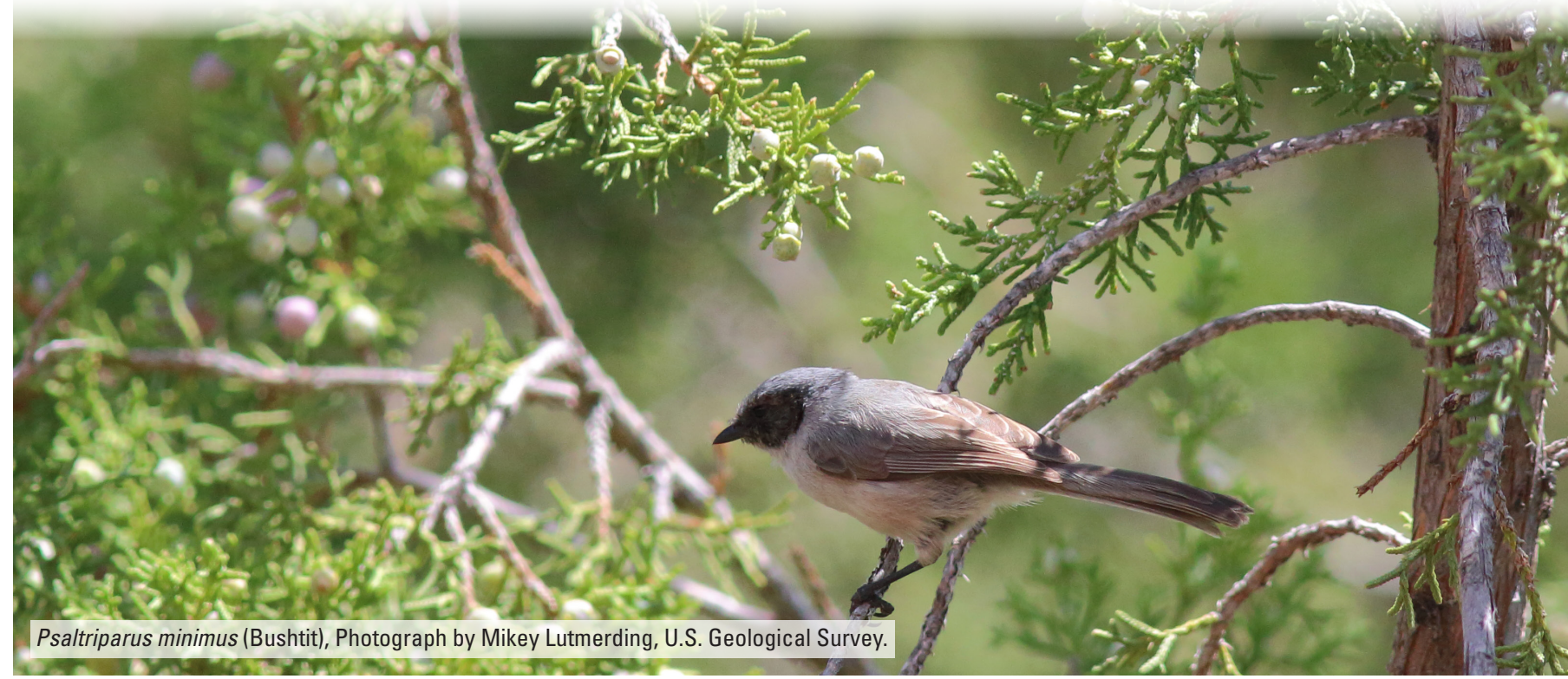




\section{Observer Participation}

Summary
- Thirty-one observers conducted surveys. Two
observers employed by CONABIO conducted
more than one-third of the surveys, and many
of the other observers received reimbursements
for travel expenses.
There is likely a relatively small pool of observers
available with the skills and resources necessary to
conduct BBS surveys in the locations of interest.
- Safety and security concerns exacerbate the
challenges of recruiting new observers to
conduct roadside surveys.
- The pool of local observers available to conduct
surveys is likely to remain small, and this may
prove to be the biggest obstacle to the future
success of the Mexican BBS program.

\section{Number of Observers and Turnover}

Thirty-one observers conducted BBS surveys (table 3). More than one-third ( 37.3 percent) of the 252 total surveys were conducted by two observers hired by CONABIO (observer 1180166 conducted 49 surveys in Chihuahua; observer 990849 conducted 45 surveys in Sonora and Baja California). Ten observers conducted only 1 survey each, and an additional 10 observers conducted 2-5 surveys. The highest participation occurred in 2015 when 16 observers conducted 44 surveys (table 3 ).

As might be expected, the largest number of surveys were conducted in States with the most observers, and only 4 of 31 observers conducted surveys in multiple States (table 3). Eight observers participated for 5 or more years, including two observers who participated for 10 of the 11 years (table 3 ).

Patterns of change in BBS counts of a species over time reflect changes in population size and changes in the counting process (Sauer and others, 1994). Observers are an important component of the counting process, so differences in skill and field craft between observers can result in differences in counts, even when population sizes haven't changed. Analyses that model population change can control for observer turnover by including observers as covariates, but clearly it is beneficial to minimize observer turnovers that occur over time (Link and Sauer, 1998; Sauer and others, 1994). For this reason, it is important that participants be encouraged to perform annual surveys on the same routes for as many years as possible. In this regard turnover was not a significant problem in Mexico; only 6 of 53 routes were surveyed by more than one observer. In 3 of those 6 routes, only the first of multiple years had been surveyed by a different observer (table 1.1).

\section{Identification Skills, Training, and Resources}

The BBS requires observers to be able to identify all species typically encountered on a given BBS route, by sight and sound. Identification of approximately 300 species in the seven-State focal area during the summer, including some species that require care in identification, represents an appreciable level of skill. Considerable time and training are needed to accrue that skill and to achieve the proficiency needed to effectively use it during the fifty 3 -minute point counts that compose a BBS route. The increasing availability of on-line training materials (for example, sound recordings) has facilitated the learning process, but the learning curve is nonetheless steep. To advance this process, CONABIO conducted a series of training workshops throughout northern Mexico (Humberto Berlanga García, CONABIO, oral commun., 2019). But considering the comparatively low number of observers who ultimately participated in the Mexican BBS, it is reasonable to expect that the growth of the program may continue to be limited by the paucity of people who possess the required skill set.

Moreover, the ability to conduct surveys presupposes that skilled observers also possess sufficient resources, namely access to transportation, time, and funds. Insufficient resources may limit volunteer participation. Indeed, funds were available to reimburse observers in all years except 2016 (Vincente Rodríguez-Contreras, CONABIO, oral commun., 2020), and in that year the number of surveys conducted dropped from 44 to 16 (table 1).

\section{Safety and Security}

In addition to being constrained by the availability of skilled observers with the necessary resources, observer recruitment probably has been hampered by safety concerns in the Mexican border States. Mexico has experienced dramatic increases in crime and violence over the last decade (2011-20). For perspective, during President Felipe Calderón's administration (2006-12), no other country in the Western Hemisphere had seen such a large increase in homicide rate or absolute number of homicides (Calderón and others, 2018). The greatest increases in violence have occurred since 2008, the first year of the Mexican BBS. The trend in violence continued under President Enrique Peña Nieto (2012-18) when the annual average number of homicides grew by 20 percent of those during the Calderón administration.

Although these data refer to all of Mexico, increases in violence were particularly acute in the States that compose the Mexican BBS focal area. For example, two of the States with the largest number of homicide cases in 2017 were Baja California and Chihuahua; Baja California Sur had the second largest percentage increase in homicide cases (Calderón and others, 2018). Moreover, violence at some locations within the border States has become so pronounced that displacement of populations has occurred; some towns have been described 
as ghost towns, including some towns close to the border with Texas in the States of Coahuila and Tamaulipas (Beittel, 2018).

Because of this violence, the U.S. Department of State has issued travel advisories warning of the risks associated with traveling to the region (for example, U.S. Department of State, 2008). These alerts presumably contributed to the limited participation in the Mexican BBS program by United States citizens. The violence has also limited the ability of Mexican residents to safely run routes in many areas. Moreover, even though the dramatic escalation of violence may understandably have contributed to the low participation during the first years of the project, a recent review of travel advisories indicates that risks of violence in the region have continued (U.S. Department of State, 2021).

Increases in crime and violence have been largely attributed to organized crime and drug trafficking coupled with endemic corruption (Beittel, 2018), and it has been argued that long-term institutional reform will be necessary before the problem is resolved. Consequently, it may be unrealistic to expect a substantial increase in participation in the Mexican BBS.

\section{Conclusions}

The number of observers who have conducted BBS surveys in Mexico is quite small (31 observers), and only two hired observers conducted more than one-third of the surveys. Owing to the experience, training, and resources required to conduct BBS surveys, the pool of potential new observers in the seven-State focal area is likely limited. Moreover, ongoing safety and security concerns will almost certainly exacerbate the challenges of recruiting new observers. Therefore, the availability of volunteer observers to conduct surveys, in the areas where surveys are required, likely will remain one of the biggest obstacles to the success of the Mexican BBS program. Difficulty in recruiting observers could be exacerbated if funds are no longer available to continue to pay field observers.

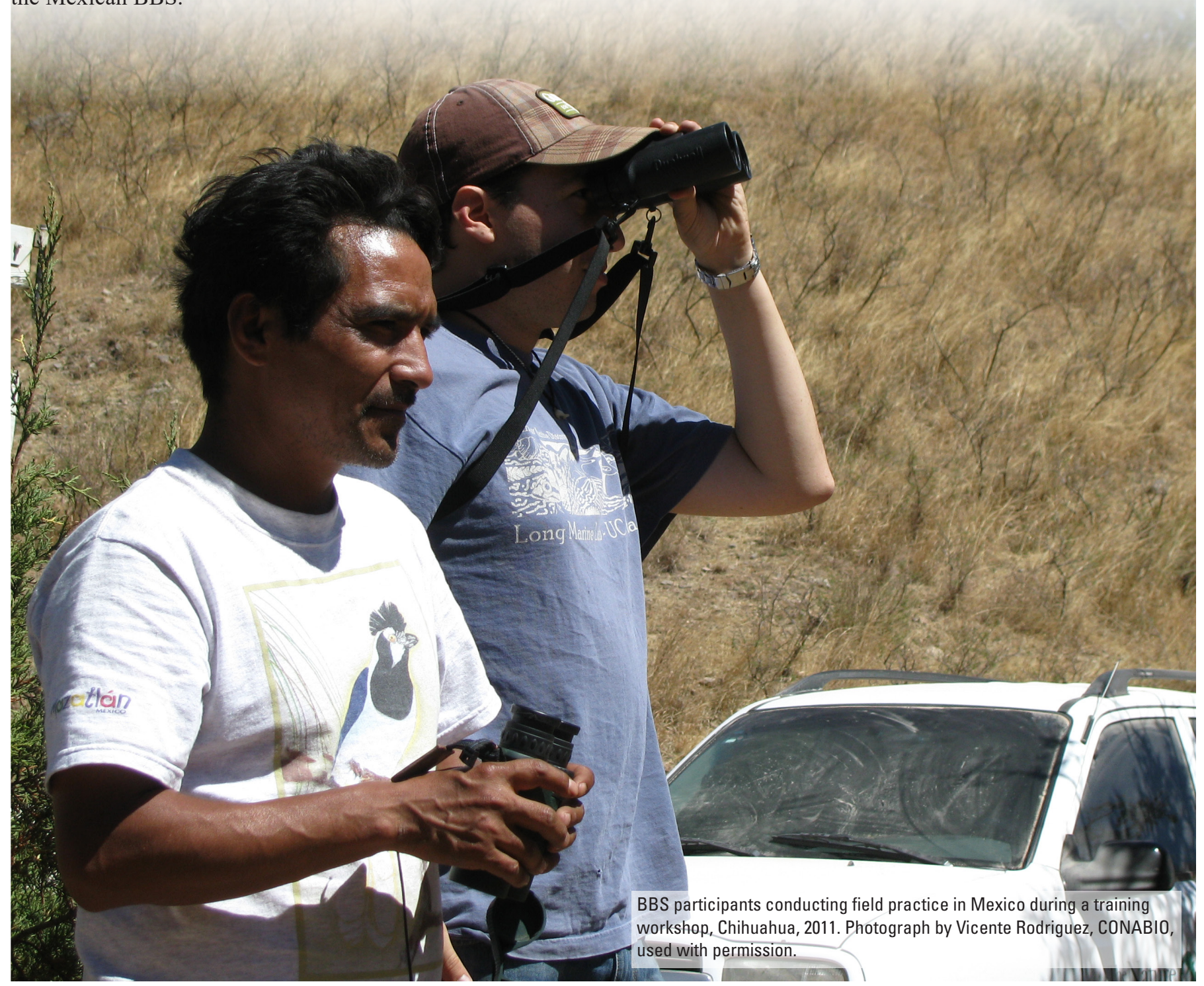


Table 3. Tallies of the number of Breeding Bird Surveys conducted by 31 observers, by each Mexican State and by year, during 2008-18.

[Observers are identified by unique numbers assigned by Breeding Bird Survey staff; No., number; A "_- “ indicates there are no data from an observer for that particular state or year]

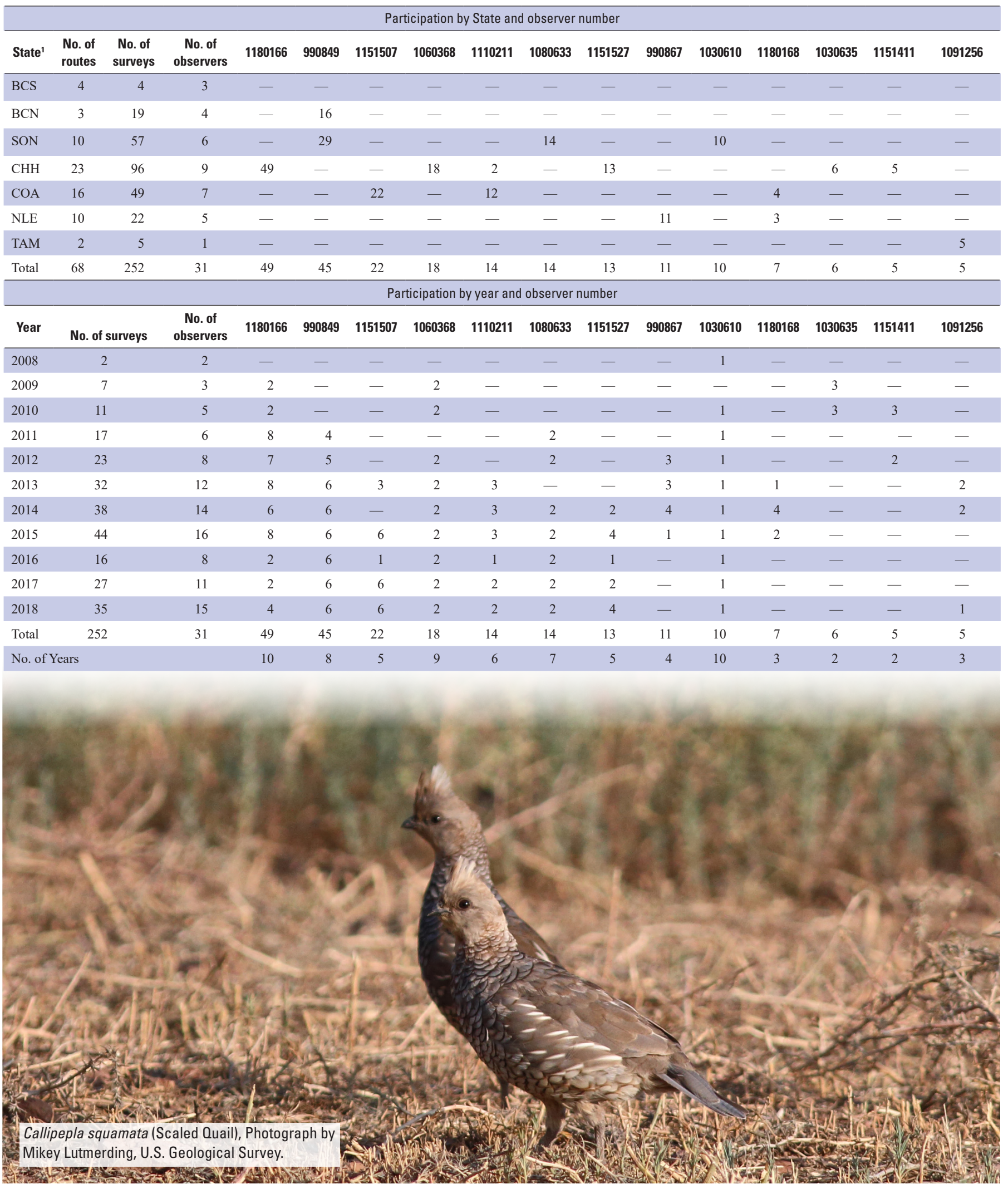


Table 3. Tallies of the number of Breeding Bird Surveys conducted by 31 observers, by each Mexican State and by year, during 2008-18.-Continued

[Observers are identified by unique numbers assigned by Breeding Bird Survey staff; No., number; A “- " indicates there are no data from an observer for that particular state or year]

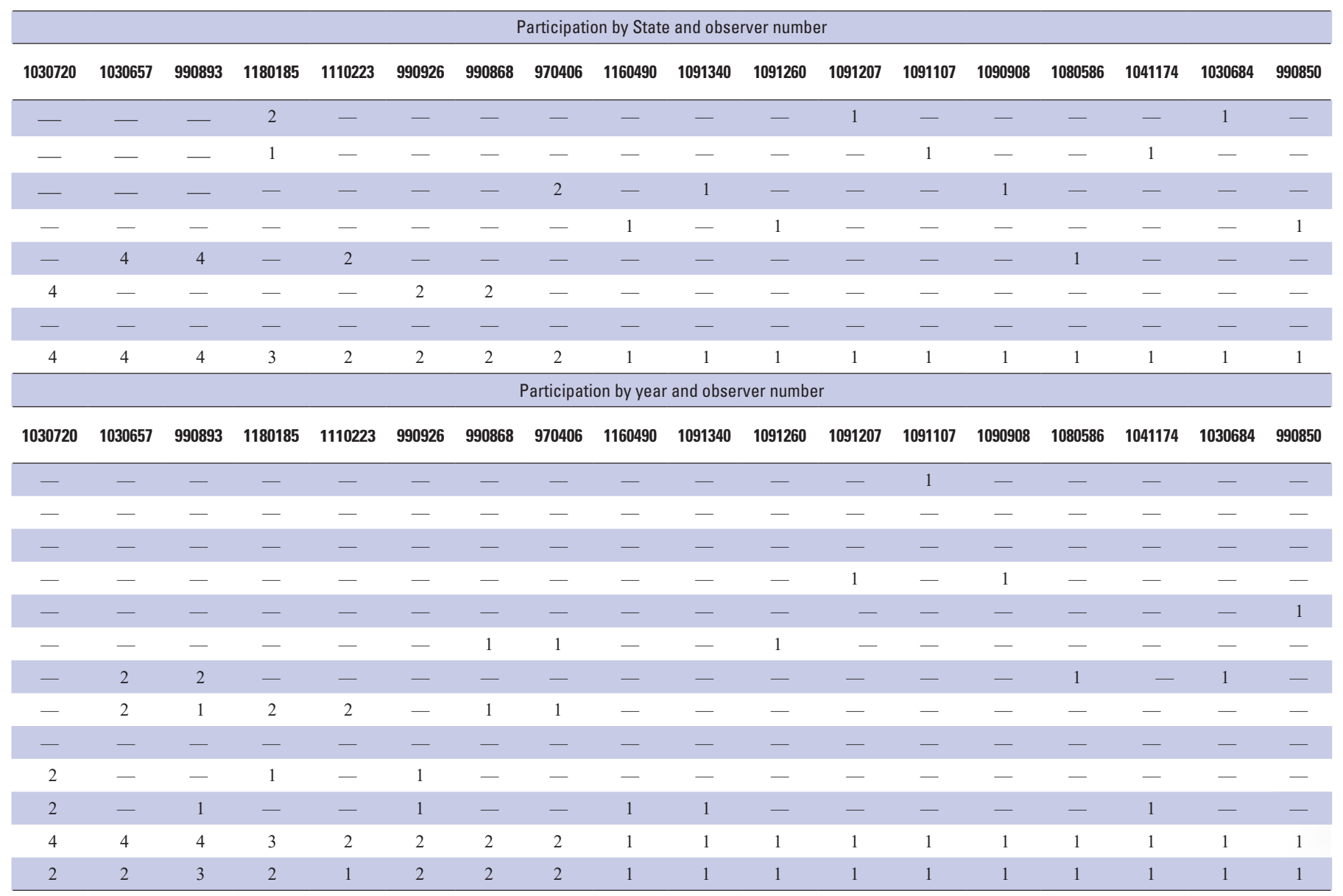

'State abbreviations: BCS, Baja California Sur; BCN, Baja California; SON, Sonora; CHH, Chihuahua; COA, Coahuila; NLE, Nuevo León; TAM, Tamaulipas.

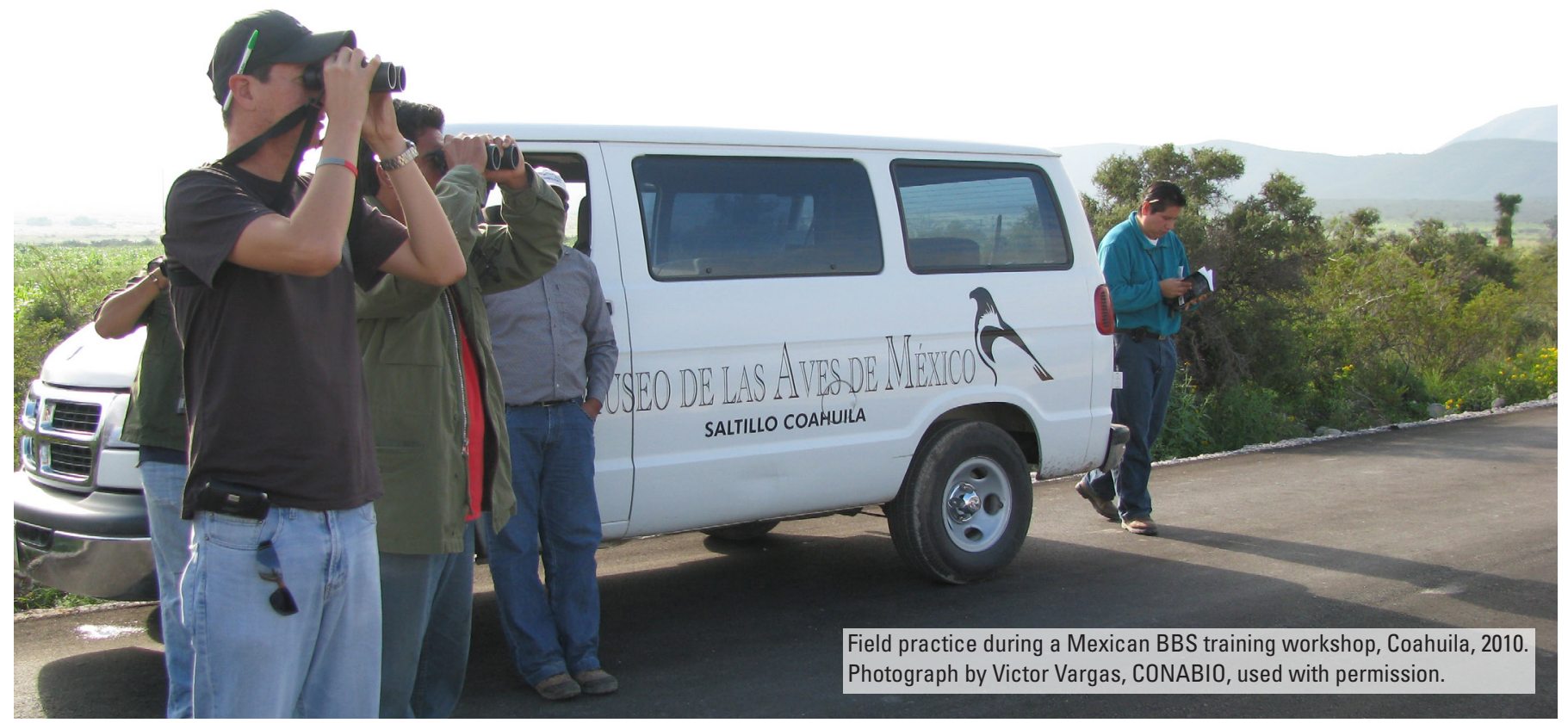




\section{Data Quality and Vetting}

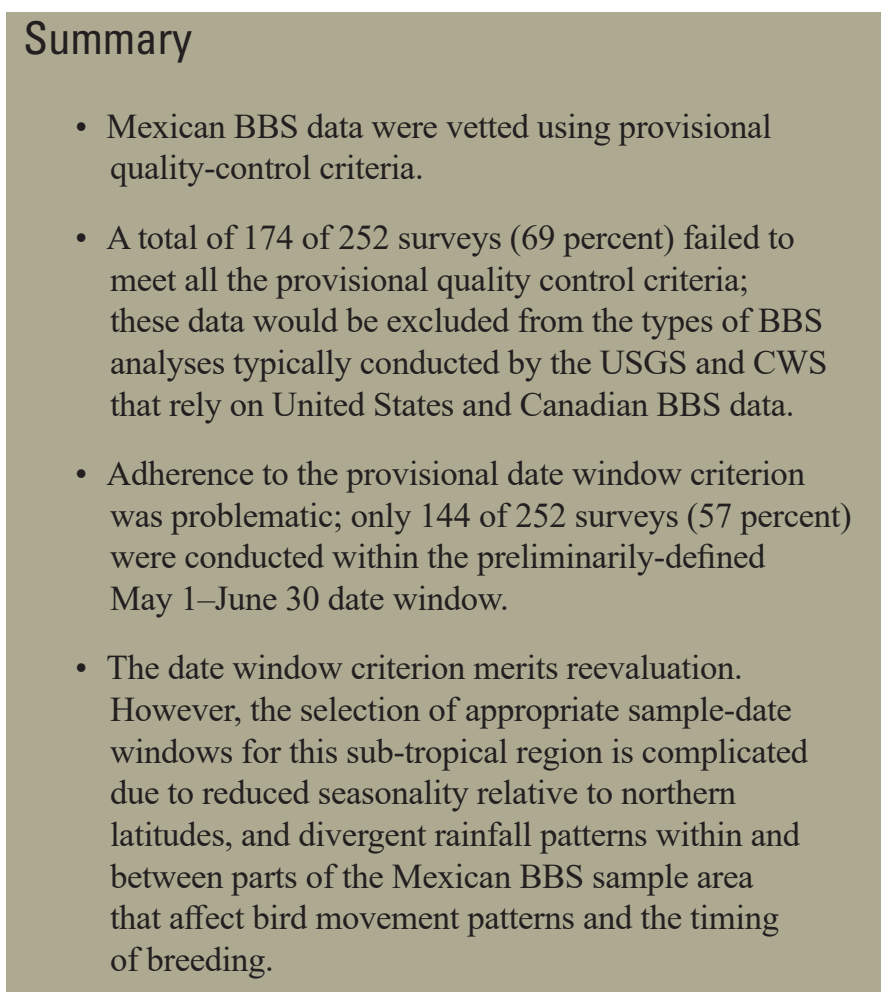

\section{The Need for Screening Count Data}

Not all data collected from BBS surveys are suitable for analysis. As previously mentioned, BBS counts reflect both the population size and the counting process. The methodology of the BBS is designed to minimize effects of the counting process to produce a reliable index that tracks changes in the population size. Because of this, surveys that fail to meet the BBS's criteria for time of year, time of day, survey duration, weather condition, and other protocol requirements aimed at standardizing counts are considered not comparable across time and space. Data from the United States and Canada are therefore routinely screened to remove nonconforming data, using quality-control criteria that reflect the BBS protocol requirements.

Quality-control screening is also required for Mexican BBS data before they can be incorporated with the data from the United States and Canada. Modifications to some of the protocols and screening criteria used in the United States and Canada are required, however, because ecological conditions in Mexico differ from conditions in most of the United States and Canada. For example, owing to Mexico's sub-tropical latitudes and unique weather patterns, breeding phenology and synchrony may differ from that in much of the United States and Canada. Consequently, when protocols for the Mexican BBS were developed prior to the initiation of BBS sampling in 2008, coordinators needed to select time of year (date window) requirements that would be appropriate for the Mexican focal region. Based on information available at the time, the time of year protocols in use in some regions of the southern United States (May 1 through June 30) were provisionally adopted, with the expectation that the appropriateness of these dates would be re-evaluated at some yet to be defined date. Because of the still provisional nature of the date window criterion, no formal screening of the Mexican BBS dataset has been conducted. Nonetheless, the following section describes the quality-control criteria used in this report, which were developed for the purpose of provisionally summarizing the number of surveys likely to represent comparable indexes of abundance.

\section{Criteria for Screening Count Data}

The BBS in the United States and Canada uses a "RunType Code" system to identify data that are acceptable for trend analyses as conducted by the USGS and CWS. For further information about this system, see the file "RunType. pdf," available at https://doi.org/10.5066/P9J6QUF6. A completed survey receives a RunType Code of 1 if all the following three criteria are met:

A. The starting location and direction of the route were randomly determined.

B. The standard BBS field counting protocol was followed. [The standard field protocols described here refer to the method of counting, for example, 3-minute counts by one observer, once per year. See Robbins and others (1986) for further details.]

C. The survey was performed under the following five field conditions. Surveys meeting all five field conditions receive a "QualityCurrentID" score of 1.

1. Completed in the pre-defined date window for the region (between May 1 and June 30 for Mexico).

2. Started 20 minutes or less before or 30 minutes or less after the official start time.

3. Completed in 6.5 hours or less.

4. At least 45 of the 50 point counts on the route were completed.

5. The survey was conducted under acceptable weather conditions (for details, see the file "RunType.pdf" at https://doi.org/10.5066/P9HE8XYJ).

\section{Number of Comparable Surveys}

All 68 routes sampled were created randomly, so all surveys met criterion A listed above. All surveys were conducted using the standard BBS field protocol, so all surveys met criterion B as well. But only 78 (31 percent) of the 252 surveys were performed under all the field conditions described in criterion C. Only these 78 surveys would receive 
a QualityCurrentID designation of 1 and therefore a RunType Code designation of 1 (Table 4). The other 174 surveys would receive a RunType Code of 0 and therefore would be deemed unacceptable for inclusion in trend analyses typically conducted by USGS and CWS biologists.

With regard to the five field condition criteria (Criterion C), nearly all surveys (greater than 99 percent) were conducted under acceptable weather conditions, and likewise, nearly all (greater than 99 percent) met or surpassed the required threshold of 45 point counts completed (table 4 , table 1.2). However, only 159 of the 252 surveys ( 63.1 percent, table 4 , table 1.2 ) began at an acceptable start time (within 20 minutes or less before or 30 minutes or less after the designated, official start time). All but 3 of the 93 surveys that failed this criterion began more than 30 minutes after the official start time. Late starts generally extend the end time, and this is noteworthy because avian activity declines as mid-day approaches; therefore,

Table. 4 The number of Mexican Breeding Bird Surveys (out of a total of 252) that meet each quality control criterion. Only surveys that meet all quality-control criteria are assigned a QualityCurrentID value of 1 , which is routinely used to determine which United States and Canadian Breeding Bird Survey data should be included in statistical analyses typically conducted by U.S. Geological Survey analysts. Because the date window criterion is considered provisional, summaries are provided both by including and excluding the date window criterion.

$[\leq$, less than or equal to; $\geq$, greater than or equal to $]$

\begin{tabular}{|c|c|c|}
\hline \multirow{2}{*}{ Criteria } & \multicolumn{2}{|c|}{ Surveys meeting criteria: } \\
\hline & Number & Percent \\
\hline 1. Date window (May 1-June 30) & 144 & 57.1 \\
\hline $\begin{array}{l}\text { 2. Start time window }(\leq 20 \mathrm{~m} \text { early, } \\
\leq 30 \mathrm{~m} \text { late })\end{array}$ & 159 & 63.1 \\
\hline 3. Duration window $(\leq 6.5 \mathrm{hr})$ & 223 & 88.5 \\
\hline $\begin{array}{l}\text { 4. Route completed (completed } \\
\geq 45 \text { stops) }\end{array}$ & 250 & 99.2 \\
\hline 5. Acceptable weather: & 250 & 99.2 \\
\hline Meet criteria 2 through 5 & 131 & 52.0 \\
\hline Meet all criteria (QualityCurrentID=1) & 78 & 31.0 \\
\hline
\end{tabular}

Chordeiles minor (Common Nighthawk), Photograph by Mikey Lutmerding, U.S. Geological Survey.

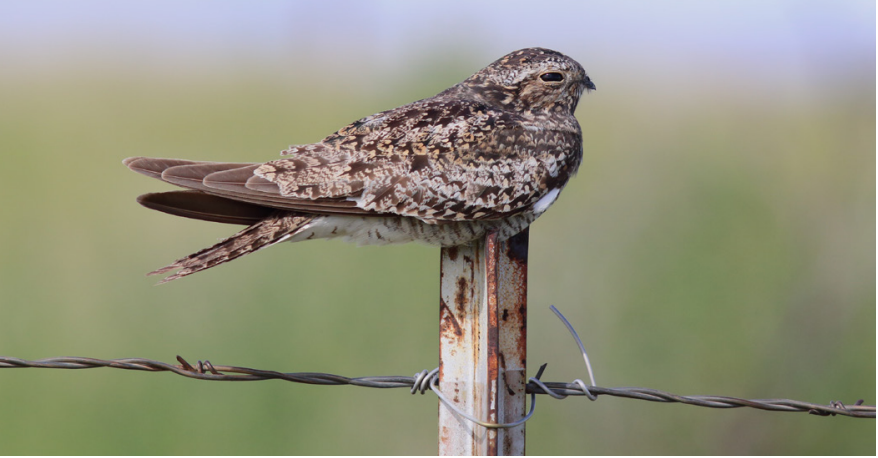

detectability is reduced, especially in arid areas and in southern latitudes (Blake, 1992). Late end times were also a problem for 29 surveys (11.5 percent) that exceeded the acceptable survey duration of 6.5 hours (table 4 , table 1.2).

The reason for the late starts is unclear, but we may speculate that this is at least partially a consequence of the early required start times and possible remoteness of the start locations relative to the residences of the observers. Late end times may in some instances be correlated with late start times, but late end times may typically be a consequence of factors such as a lack of scouting by observers (that may result in taking wrong turns or taking too long to find correct stop locations, for example), encountering unforeseen circumstances such as washed out or closed roads, or problems with vehicles. Many of these problems can be addressed by improving training, preparation and scouting.

The criterion most often violated was the sample date window. Of the 252 surveys, only 144 (57.1\%) were conducted within the provisional 61-day May 1 to June 30 date window (table 4). Seventeen of those were conducted in May; the remaining 127 surveys were conducted in June (table 1.2). More than 6 times as many surveys (103) were conducted in July than in May, even though July was outside of the provisional sampling window. The provisional date window was inherited from the southwest United States surveys and likely merits re-evaluation (see discussion in section "Date Window Considerations"). In fact, although only 78 surveys met all the screening criteria, if the date window criterion is disregarded, slightly more than one-half of the surveys (131 surveys, 52.0 percent) would receive a RunType Code designation of 1 (table 4 ).

\section{Date Window Considerations}

In the temperate region, especially in the more northern latitudes where the BBS originated, the breeding season for most species is relatively brief, and most birds initiate breeding at roughly the same time (that is, there is high breeding synchrony). This means a relatively narrow BBS date window can successfully encapsulate the breeding activity of most northerly breeding species. Accordingly, BBS protocols for most of the United States and Canada permit sampling during a 42-day period between May 27 and July 7; however, there are exceptions where necessary to better align with local breeding patterns. Regional exceptions include desert and southern areas where surveys are permitted to begin as early as April 20 and some alpine areas where surveys are permitted as late as July 15 . Prior to the first (2008) field season, the Mexican BBS coordinators provisionally adopted the 61-day date window used in portions of the southwestern United States (May 1June 30), but coordinators recognized that re-evaluation of the date window would be necessary.

The longer date window for Mexico accounts for the facts that seasonality in northern Mexico is more protracted than at higher latitudes and patterns of rainfall affect breeding activity. Consequently, breeding activity in the region is less 
synchronous than in most of the United States and Canada, which means that it may not be possible to define a relatively narrow date window that includes the breeding activity of most species. For example, northwest Mexico experiences a monsoon season from July through September, during which time a substantial proportion of the annual rainfall occurs (Douglas and others, 1993), and a considerable amount of breeding occurs during this period. Indeed, even though there is much breeding activity as early as late April, Short (1974) identified 16-21 Sonoran species whose nesting activity occurs only during the summer rainy period, especially late July to early August. Incidences of breeding during the summer rainy season may help explain why so many observers chose to conduct their BBS surveys in July, outside the provisionally accepted date window (table 1.2). To complicate matters further, other species have been identified as having bimodal (both spring and summer) breeding seasons (Short, 1974).

Owing to the extent of late season breeding, one might consider it efficacious to shift the survey window into accord with rainfall patterns in localities where most bird species are monsoon season breeders. However, shifting sampling periods to co-occur with the monsoon season could lead to several complications. For example, the breeding activities of early breeders might then fall outside the acceptable date window. Moreover, monsoon conditions vary considerably across the Mexican BBS region (fig. 4) and may be restricted to geographical areas that are smaller than the operational units for which the BBS sets its protocol requirements.

In addition to the inadequacy of shifting the date window by region, it would be problematic to adapt BBS methods for use in the region by extending the length of the acceptable date window in an attempt to encompass the breeding activities of more species. Doing so would make it likely that for many individual species the date window would include longer periods of time when breeding activities are not occurring. If detectability differs between the breeding and nonbreeding periods (for example, owing to differences in vocalization rates), then the heterogeneity in detectability introduced by lengthening the date window may obfuscate the ability to statistically detect trends, especially if the dates individual surveys are conducted do not remain rather consistent from year to year. Moreover, if a higher percentage of surveys in Mexico are conducted outside the breeding season, relative to the United States and Canada, and this results in heterogeneous detectability, then the indexes of abundance derived from these surveys may not be comparable among regions. And because these indexes are used to derive population size estimates, for example, extending the date window could potentially have unintended consequences for any conservation plans that make use of these derived parameters.

Yet another problem with extending the date window is that not all nonbreeding birds detected will be representatives of the local breeding population, especially late in the summer. For example, some species undergo molt migrations, whereby they leave their breeding grounds to molt in resource rich areas distant from their breeding and wintering grounds
(Leu and Thompson, 2002). The monsoon region of the southwest United States and northwest Mexico are particularly known for this phenomenon (Rohwer and others, 2005). At least 19 species have been identified that have post-breeding molt migrations to the northwest Mexico monsoon region (Pyle and others, 2009). Therefore, an unknown proportion of birds detected during Mexican BBS surveys conducted in July or later may be nonbreeding birds that have arrived from northern latitudes or from other parts of the Mexican BBS sampling area. To further complicate the interpretation of late-season BBS data, at least five species are known to migrate thousands of kilometers south from their primary breeding grounds in the United States and Canada to breed for a second time within the same BBS survey season in the Mexico monsoon region (Rohwer and others, 2009).

\section{Conclusions}

An appreciable number of surveys did not meet provisional quality-control requirements. Steps could be taken to reduce this number. In some cases, problems may be reduced simply by conveying to the observers the importance of scouting routes to become familiar with them, starting on time, keeping the pace up, and not taking an excessive number of breaks between points. In other cases, problems may be the result of poor road conditions and may therefore require revision or retirement of routes.

The quality-control issue that requires the most attention is the sampling date window. For example, only 17 surveys were conducted in May, within the provisional May-June date window, whereas 103 were conducted in July, outside of the provisional sampling date window. The importance of conducting surveys within the sampling date window specified for this geographic region, which has been provisionally determined based on regional differences in breeding phenology, should be impressed upon the observers. However, it is also important to determine why so many observers conducted the surveys outside of the prescribed time frame. Did the observers have reason to suspect that dates in July would be more appropriate for detecting breeding birds? Concerns about the selection of an appropriate date window have not yet been adequately addressed but, owing to the protracted and asynchronous patterns of breeding in the region, exclusion of the monsoon period from the date window may be problematic. However, as discussed above, it is unlikely that the date window can be expanded to adequately encapsulate the breeding activity for most of the species breeding in northern Mexico without confounding the results owing to increased intraspecific seasonal variation in detection probabilities. This may be an unsurmountable limitation of the BBS methodology for sampling Mexican bird populations, as the BBS was developed for sampling bird populations in more temperate latitudes. 

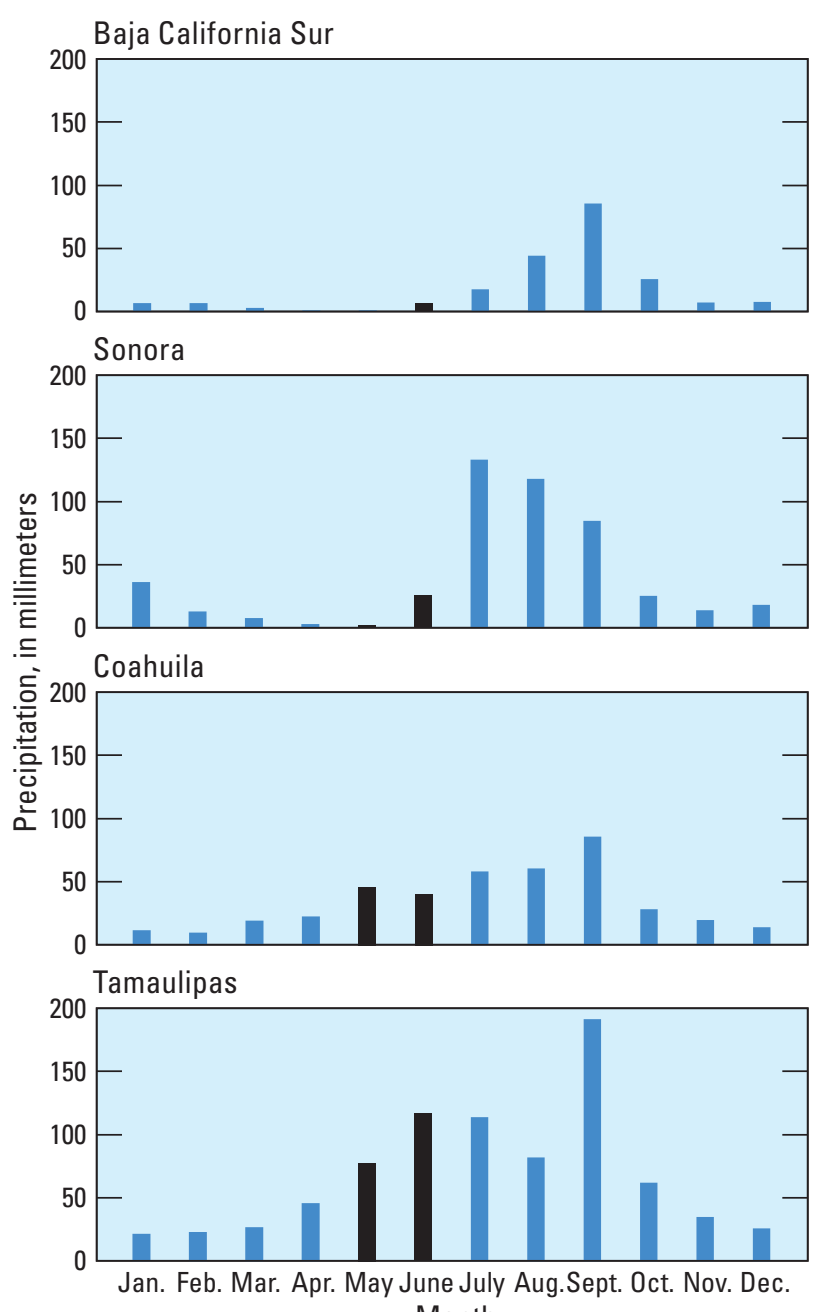

Baja California Norte

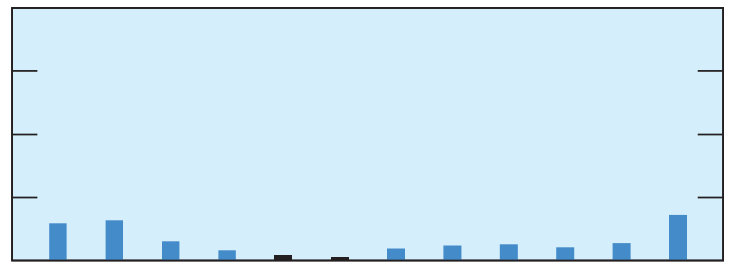

Chihuahua

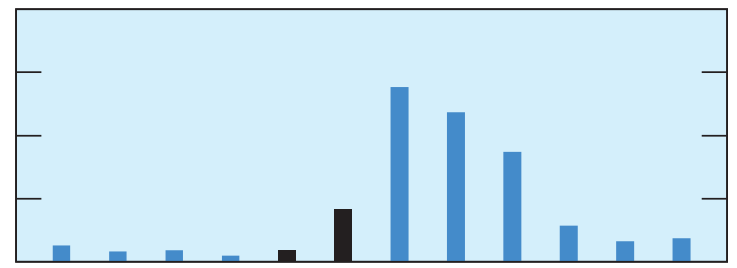

Nuevo León

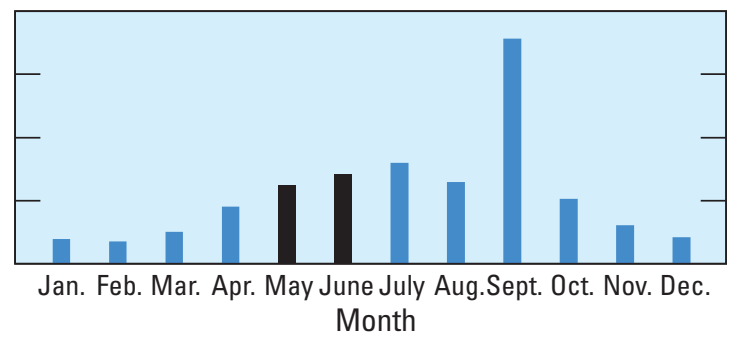

Figure 4. Average monthly rainfall during 2008-18 for each State in the Mexican Breeding Bird Survey focal area. Black bars highlight monthly precipitation during the currently accepted date range for conducting Breeding Bird Surveys in Mexico (May and June). Data source: Gobierno de México, Comisión Nacional del Agua, https://www.gob.mx/conagua.

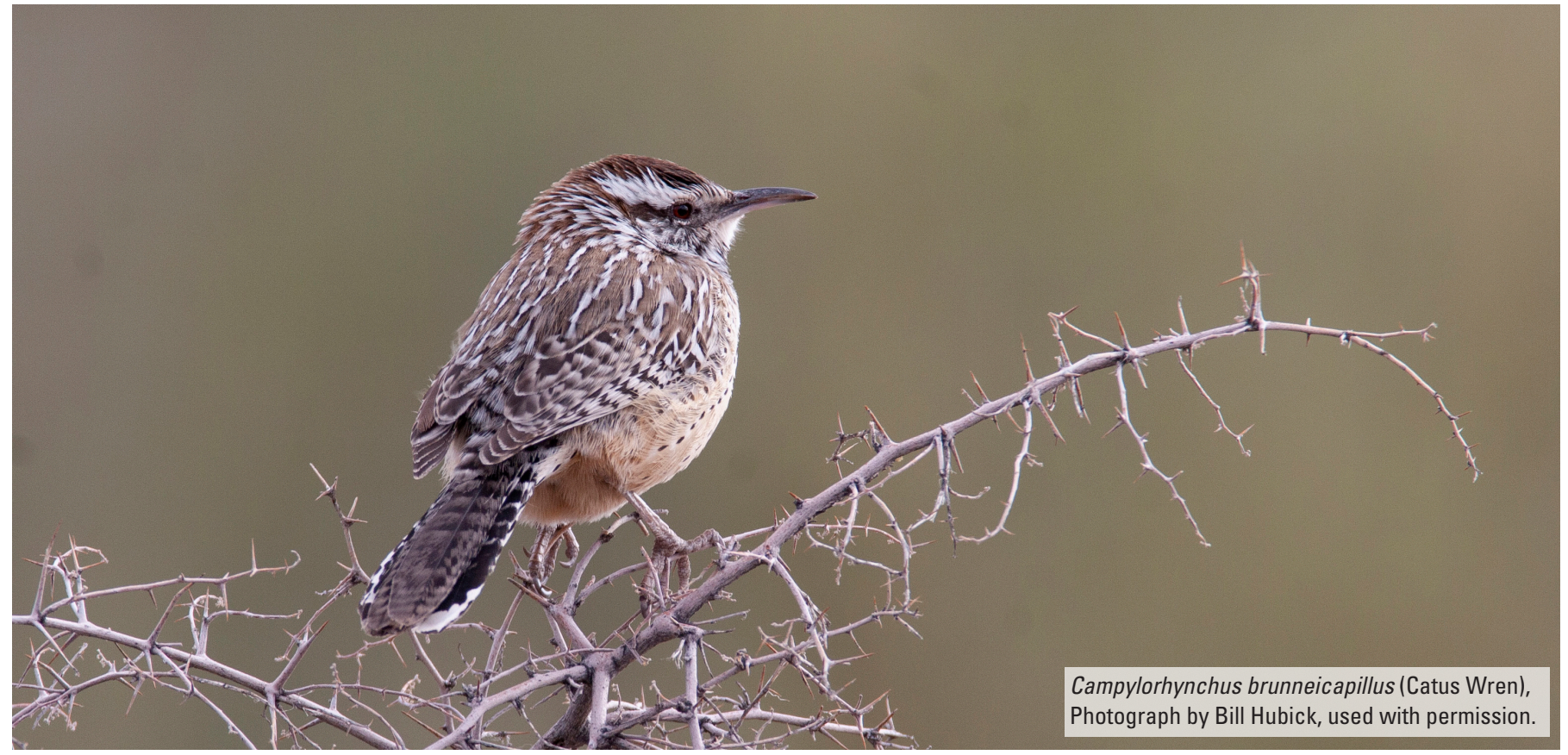




\section{Bird Records}

Summary
- A total of 8,414 BBS records from 269 taxa
( 92.2 percent of all 9,122 records reported) were
tentatively identified as potentially valid breeding
records. Another 708 records ( 7.8 percent of the total)
were flagged as likely misidentifications, unidentified
taxa, or non-breeders on the routes where they were
reported, or there were problems with the records
(for example, no count data).
Quality-control concerns dictate that BBS data be
vetted in comparison with verified regional distribu-
tional and breeding information to accurately pin-
point possible identification errors and nonbreeders.
However; lists based on verified regional distribution
and breeding information do not currently exist and
would need to be developed.

\section{Quality-Control Criteria Used to Evaluate Species Data}

For exploratory purposes, all bird records in the Mexican BBS dataset were vetted by comparison to distributional and breeding information available from a variety of sources, including in-print and on-line checklists (Avibase, 2018; Erickson and others, 2013; iNaturalist, 2018) and range maps (Berlanga and others, 2018; Cornell Lab of Ornithology, 2018a,b,c; Dunn and Alderfer, 2017; Howell and Webb, 1995; Rodewald, 2015). These resources were used to identify potential misidentifications and reports of non-breeding birds in the Mexican BBS dataset (including winter residents and transient migrants, as well as nonbreeders that may over-summer in the region or disperse to the area after breeding elsewhere).

BBS records were considered to represent the regional breeding population if these resources documented the occurrence of the species as a breeder anywhere within a State/BCR stratum. In other words, all reports of a species were considered acceptable breeding records in a State/BCR stratum if distributional information indicated that breeding occurs in any part of the State/BCR stratum. BBS reports from a State/BCR stratum also were accepted in cases where no breeding documentation existed if breeding had been documented close to the stratum's border in an immediately neighboring stratum. This approach allows for the likelihood that the published distributional information was incomplete and that Mexican BBS reports offer new insights about fine-scale patterns of distribution.

As a caveat, however, it is important to recognize that, in comparison to the amount of information available for the sampled areas in the United States and Canada, the amount of distributional and breeding information available for the sampled areas in Mexico is currently limited, and the spatial and temporal resolution of the information available varies from region to region. Much remains to be learned about the distribution of birds in Mexico and about regional differences in the phenology of breeding activity. Owing to this relatively high degree of uncertainty, the screening results described here are best considered provisional.

\section{Results of Screening Data by Taxa}

In the Mexican BBS dataset, inclusive of all the RunType Code designations, there were 9,122 data records (reports of a taxon on a route in any given year), representing 349 taxa. Among these 9,122 records there were 328 data records that did not have any associated count data (that is, the taxon appeared in a survey's species list, but 0 birds were reported from each of the 50 point counts). These were omitted from further consideration. An additional 55 data records pertaining to 19 "unidentified" taxa were also omitted from further consideration because they would be of little value for trend analysis. As a result of comparison to the distributional information in the checklists and range maps listed above, 61 taxa were recognized as occurring only as nonbreeders in the seven-State focal area, or regularly occurring only outside the region and were likely misidentified. Among the 269 taxa accepted as breeding within the focal area, 33 were recognized as breeding in some strata but not in others. Data records for these taxa from areas where breeding was not known were omitted from further consideration.

After omitting the records described above, 8,414 ( 92.2 percent) of the data records remained, representing 269 taxa. The omitted 708 records (7.8 percent of the total) were flagged as misidentifications, unidentified, or nonbreeders on the routes where they were reported, or as having other problems (no count data). The full list of tentatively accepted, rejected, and unidentified taxa is presented in table 1.3. Common and (or) widespread species (table 5) include 32 species reported from at least 10 of the 14 strata, 28 species reported on at least one half of the 68 routes, and 24 species reported with an average abundance of at least 50 birds/route (among species reported on 15 or more routes). Among these, 20 species were reported for 13-14 strata, on 55 or more ( 80 percent) of the routes, and (or) with an average of 100 or more birds per route (among species on 15 or more routes). The species most commonly reported included Turkey Vulture, Northern Mockingbird, Mourning Dove, White-winged Dove, Common Raven, Red-winged Blackbird, Rock Pigeon, and House Sparrow (table 5). 


\section{Conclusions}

A few steps are required to assure that quality-control procedures result in a dataset that can be relied upon as being credible and accurate. Protocols need to be established to identify questionable Mexican BBS records, solicit unusual species reports from field observers, require BBS staff and coordinators to review the records and documentation for accuracy, and create permanent documentation in the database indicating which records may represent breeding birds versus misidentifications or non-breeders. To this end, fine-scale regional lists of verified breeding occurrence are needed as a resource to accurately vet incoming Mexican BBS data.
Although general distribution patterns are known, it will nonetheless be difficult and time consuming to create verified region-specific lists of breeding species for Mexico because there is still much to be learned about seasonal distribution patterns and the breeding phenology of Mexican birds (CIPAMEX, 2003; Santana, 2005). Not only is some general knowledge about the ornithogeography of Mexican birds lacking, but owing to complicating factors such as those outlined in the "Data Quality and Vetting" section (for example, the presence of molt migrants), it won't always be obvious which species detected are indeed breeders. Without a good understanding of the breeding status of each species, our interpretation of the Mexican BBS data will be tentative.

Icterus cucullatus (Hooded Oriole),

Photograph by Bill Hubick, used with permission.

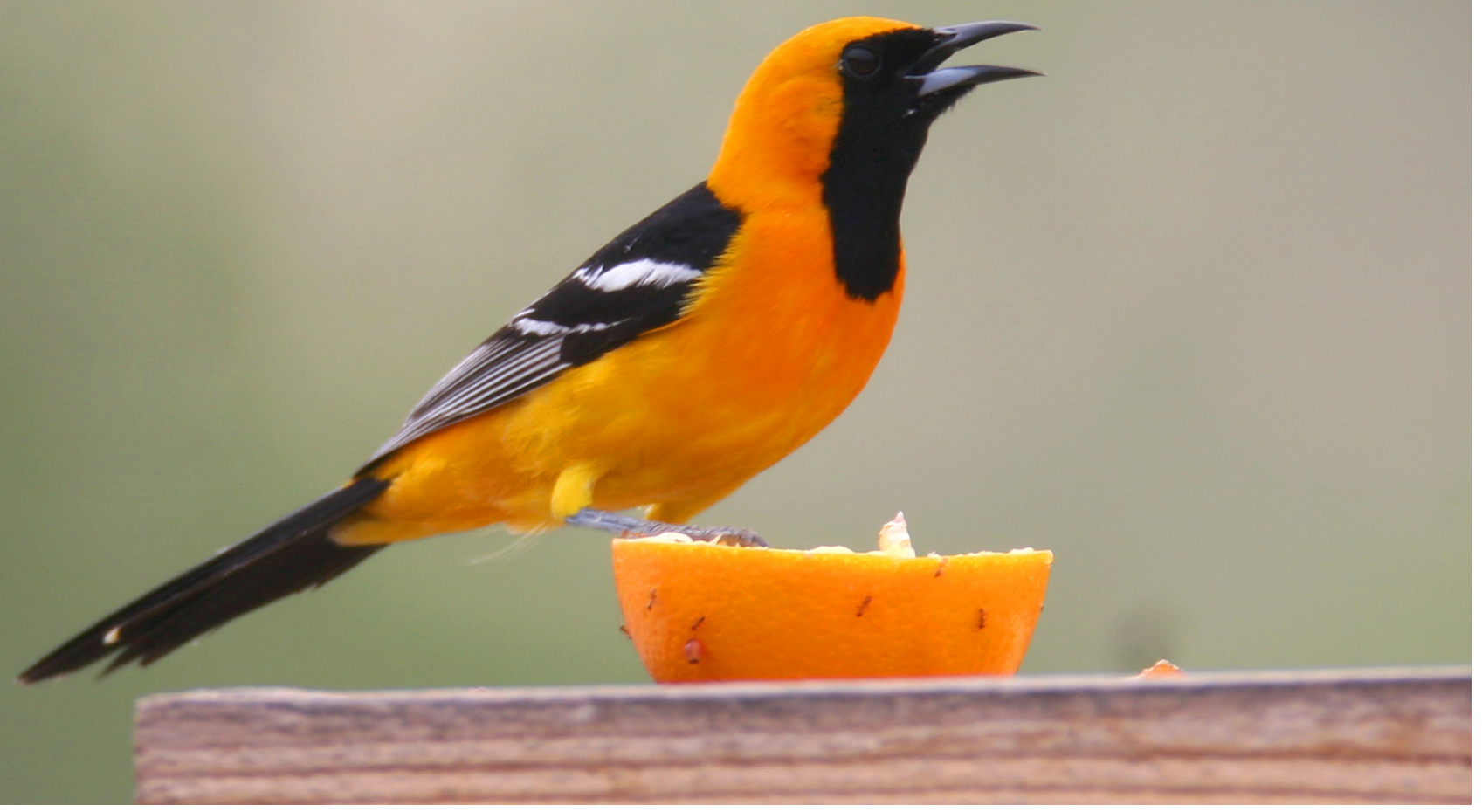


Table 5. List of 42 species commonly reported on Mexican Breeding Bird Survey routes. These include 32 species reported from at least 10 strata, 28 species reported on at least 50 percent of the 68 routes, and 24 species reported with an average abundance of at least 50 birds/route (among species reported on 15 or more routes).

\begin{tabular}{|c|c|c|c|c|}
\hline English name & Scientific name & Number of strata & Number of routes & Number of birds/route \\
\hline Scaled Quail & Callipepla squamata & 6 & 37 & 60.2 \\
\hline 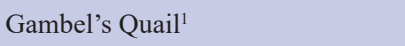 & Callipepla gambelii & 5 & 17 & 105.8 \\
\hline Rock Pigeon ${ }^{1}$ & Columba livia & 10 & 21 & 339.8 \\
\hline Eurasian Collared-Dove ${ }^{1}$ & Streptopelia decaocto & 12 & 38 & 104.4 \\
\hline Inca Dove $^{1}$ & Columbina inca & 11 & 38 & 105.4 \\
\hline Common Ground-Dove & Columbina passerina & 9 & 18 & 52.3 \\
\hline White-winged Dove ${ }^{1}$ & Zenaida asiatica & 13 & 60 & 340.0 \\
\hline Mourning Dove ${ }^{1}$ & Zenaida macroura & 13 & 60 & 368.6 \\
\hline Greater Roadrunner ${ }^{1}$ & Geococcyx californianus & 13 & 55 & 17.8 \\
\hline Killdeer & Charadrius vociferus & 11 & 33 & 24.6 \\
\hline Turkey Vulture ${ }^{1}$ & Cathartes aura & 14 & 66 & 59.1 \\
\hline Red-tailed Hawk & Buteo jamaicensis & 11 & 51 & 6.7 \\
\hline Ladder-backed Woodpecker & Dryobates scalaris & 11 & 40 & 16.1 \\
\hline Crested Caracara & Caracara cheriway & 10 & 22 & 10.4 \\
\hline American Kestrel & Falco sparverius & 12 & 43 & 10.7 \\
\hline Ash-throated Flycatcher & Myiarchus cinerascens & 12 & 39 & 32.0 \\
\hline Cassin's Kingbird ${ }^{1}$ & Tyrannus vociferans & 8 & 38 & 102.2 \\
\hline Say's Phoebe & Sayornis saya & 7 & 38 & 20.4 \\
\hline Vermilion Flycatcher & Pyrocephalus rubinus & 11 & 33 & 6.4 \\
\hline Loggerhead Shrike & Lanius ludovicianus & 10 & 49 & 18.8 \\
\hline Common Raven ${ }^{1}$ & Corvus corax & 13 & 60 & 22.1 \\
\hline Northern Rough-winged Swallow ${ }^{1}$ & Stelgidopteryx serripennis & 8 & 18 & 134.4 \\
\hline Cliff Swallow ${ }^{1}$ & Petrochelidon pyrrhonota & 9 & 21 & 126.0 \\
\hline Barn Swallow & Hirundo rustica & 9 & 48 & 81.5 \\
\hline Verdin & Auriparus flaviceps & 12 & 40 & 45.0 \\
\hline Cactus Wren & Campylorhynchus brunneicapillus & 12 & 48 & 64.5 \\
\hline Blue-gray Gnatcatcher & Polioptila caerulea & 11 & 31 & 10.6 \\
\hline Curve-billed Thrasher & Toxostoma curvirostre & 10 & 51 & 36.6 \\
\hline Northern Mockingbird ${ }^{1}$ & Mimus polyglottos & 13 & 61 & 87.4 \\
\hline House Sparrow $^{1}$ & Passer domesticus & 13 & 54 & 245.8 \\
\hline House Finch ${ }^{1}$ & Haemorhous mexicanus & 13 & 55 & 77.4 \\
\hline Lesser Goldfinch & Spinus psaltria & 11 & 27 & 58.9 \\
\hline Chipping Sparrow ${ }^{1}$ & Spizella passerina & 5 & 19 & 108.4 \\
\hline Black-throated Sparrow ${ }^{1}$ & Amphispiza bilineata & 11 & 50 & 121.7 \\
\hline Eastern Meadowlark & Sturnella magna & 4 & 21 & 79.7 \\
\hline Hooded Oriole $^{1}$ & Icterus cucullatus & 13 & 24 & 11.8 \\
\hline Red-winged Blackbird ${ }^{1}$ & Agelaius phoeniceus & 10 & 26 & 428.5 \\
\hline Brown-headed Cowbird & Molothrus ater & 12 & 43 & 45.6 \\
\hline Great-tailed Grackle $^{1}$ & Quiscalus mexicanus & 11 & 50 & 192.2 \\
\hline Northern Cardinal & Cardinalis cardinalis & 12 & 38 & 38.9 \\
\hline Pyrrhuloxia & Cardinalis sinuatus & 10 & 42 & 74.8 \\
\hline Blue Grosbeak & Passerina caerulea & 11 & 46 & 44.9 \\
\hline
\end{tabular}




\section{Data Suitable for Hypothetical Analysis}

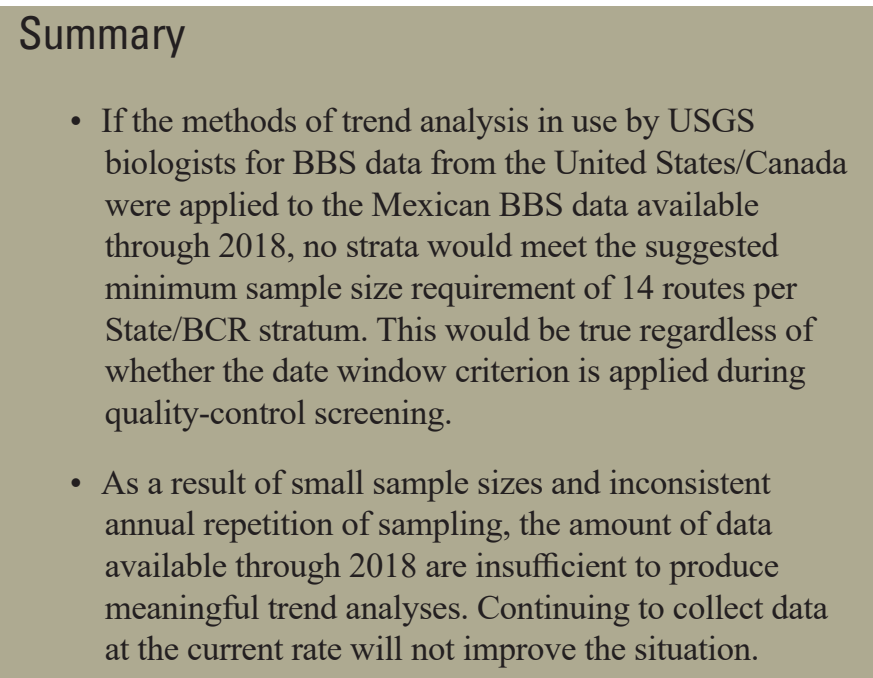

\section{Sample Size Requirements}

The data included in trend analyses are only a subset of the total data collected. Records of potentially misidentified or nonbreeding birds ("Bird Records" section) are excluded from analyses, as are records from surveys that were not run under standard conditions ("Data Quality and Vetting" section). Moreover, analytical methods impose constraints that further reduce the amount of data ultimately included in analyses. The Mexican BBS data have not been formally vetted and therefore have not been added to the dataset of the United States and Canada that typically receives analysis, nonetheless an exploratory exercise was conducted to estimate how much of the Mexican data available through 2018 would meet minimum sample size requirements for analysis according to procedures in use by the USGS for United States/Canada analyses.

There are no specific minimum sample size requirements, but a suggested guideline is that a species analysis should generally include data from at least 14 routes per stratum (Sauer and others, 2003). Protocols recently adopted by USGS staff for analysis of United States/Canada BBS data allow for small sample sizes (as few as 3 routes per stratum; Sauer and others, 2017b), but analyses including small sample sizes would not be expected to provide meaningful results unless most surrounding strata in the analysis have reasonable sample sizes (for example, data from 14 or more routes). Moreover, because only the most common species may be detected on every route, obtaining sufficient sample sizes for most species will require that more than 14 routes per stratum are sampled. Furthermore, it is expected that most routes will be sampled each year, with relatively little turnover of observers (Sauer and others, 2003).

\section{Sample Size Limitations}

Throughout the 2018 breeding season, the recommended minimum sample size of 14 routes per stratum (Sauer and others, 2003) was not obtained in any stratum (the maximum number of routes per stratum was 12 ; table 2), so after 11 years of data collection, sample sizes appear to be too small for meaningful trend analyses across the entire region. Nonetheless, as an exploratory exercise we can estimate how much available data met the bare minimum (but insufficient) threshold of three routes per stratum.

Only 78 of the 252 surveys conducted ( 31 percent) met all the quality-control criteria for inclusion in analyses ("Data Quality and Vetting" section; table 1.2). After excluding surveys that failed to meet these criteria, only 2,730 of the 8,414 records of potential breeding species remain, a reduction of 67.6 percent. If remaining data are screened on a species-by-species basis to remove all records where a species was not detected on at least three routes in a stratum, then 1,789 records from 95 species are left, which represents only 21.3 percent of the original 8,414 records from 269 species. Moreover, these records come from only 4 of the 14 Mexican strata where sampling occurred (table 6). All data collected in Baja California, Baja California Sur, Nuevo León, and Tamaulipas would be excluded from analyses, as would all data from the 12 routes sampled in the BCR 35 portion of Coahuila (see table 2 for the original sample sizes). In fact, this Coahuila stratum had one of the largest stratumspecific sample sizes (36 surveys run on 12 routes), but only 3 surveys from 2 routes met the quality-control criteria, and because analyses require data from at least three routes per stratum, none of the data collected in this stratum would be available for analysis. The unrealized value of all the excluded data ( $78.7 \%$ of all the data collected) highlights the importance of adhering to the quality-control criteria and meeting sample size requirements, especially when considering the effort expended to collect the data.

The data available for analysis after culling would include records from 23 species in the BCR 36 portion of Coahuila, 59 species in the BCR 33 portion of Sonora, and 50 and 52 species in the BCR 34 and BCR 35 portions of Chihuahua, respectively. To reiterate, none of the strata had sample sizes of 14 or more. Furthermore, concerns about the small sample sizes are not restricted to the total number of routes surveyed in each stratum. Figure 1 and a comparison of the number of routes surveyed versus the number of surveys conducted (table 6) show that there has been insufficient year-to-year repetition of the surveys to provide meaningful data for analysis; many routes have been sampled only once or a few times.

This summary highlights the paucity of data suitable for analysis if all quality-control criteria mentioned in the "Data Quality and Vetting" section are strictly applied. However, if the date window criterion (which merits reevaluation) is disregarded, the number of surveys meeting the remaining quality-control criteria would increase from 78 to only 
Table 6. Data from Breeding Bird Survey Routes in Mexico that would meet the absolute minimum (but not sufficient) requirement for inclusion in trend analyses according to methods typically used by the U.S. Geological Survey for United States/Canada Breeding Bird Survey analyses. This list includes 1,789 records of 95 potentially breeding species detected on three or more routes in at least one State/Bird Conservation Region stratum, after first removing records from routes that failed to meet all quality-control criteria (table 1.2). The four listed strata include at least one species reported from three or more routes. Tallies show the number of routes (N) and surveys (S) each taxon was reported from, as well as the total number of individuals reported (n).

[No., number of; BCR, Bird Conservation Region; A “_- “ indicates there are no data or insufficient data $(\mathrm{N}<3)$ ]

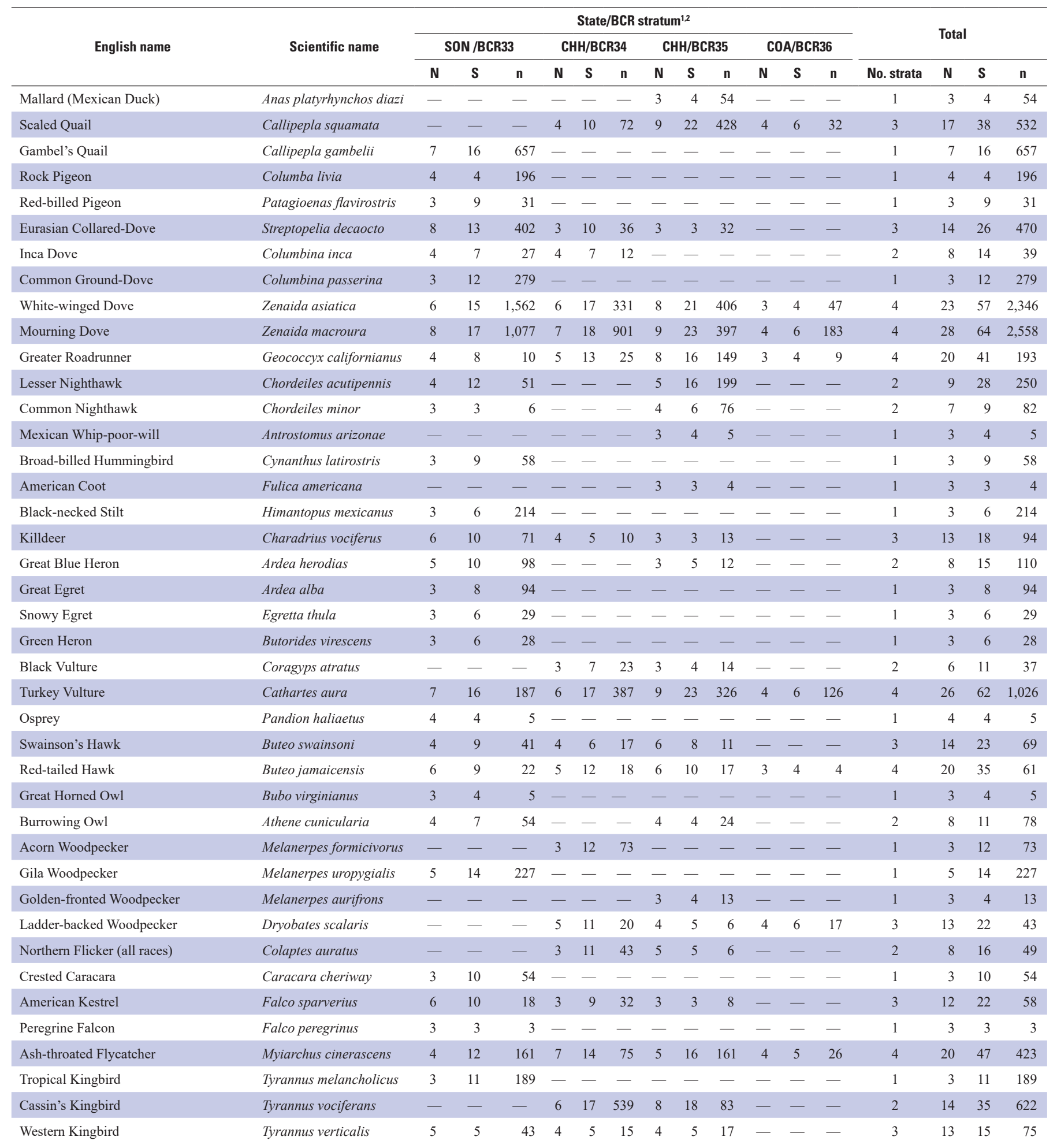


Table 6. Data from Breeding Bird Survey Routes in Mexico that would meet the absolute minimum (but not sufficient) requirement for inclusion in trend analyses according to methods typically used by the U.S. Geological Survey for United States/Canada Breeding Bird Survey analyses. This list includes 1,789 records of 95 potentially breeding species detected on three or more routes in at least one State/Bird Conservation Region stratum, after first removing records from routes that failed to meet all quality-control criteria (table 1.2). The four listed strata include at least one species reported from three or more routes. Tallies show the number of routes (N) and surveys (S) each taxon was reported from, as well as the total number of individuals reported (n).-Continued

[No., number of; BCR, Bird Conservation Region; A “_ “ indicates there are no data or insufficient data $(\mathrm{N}<3)$ ]

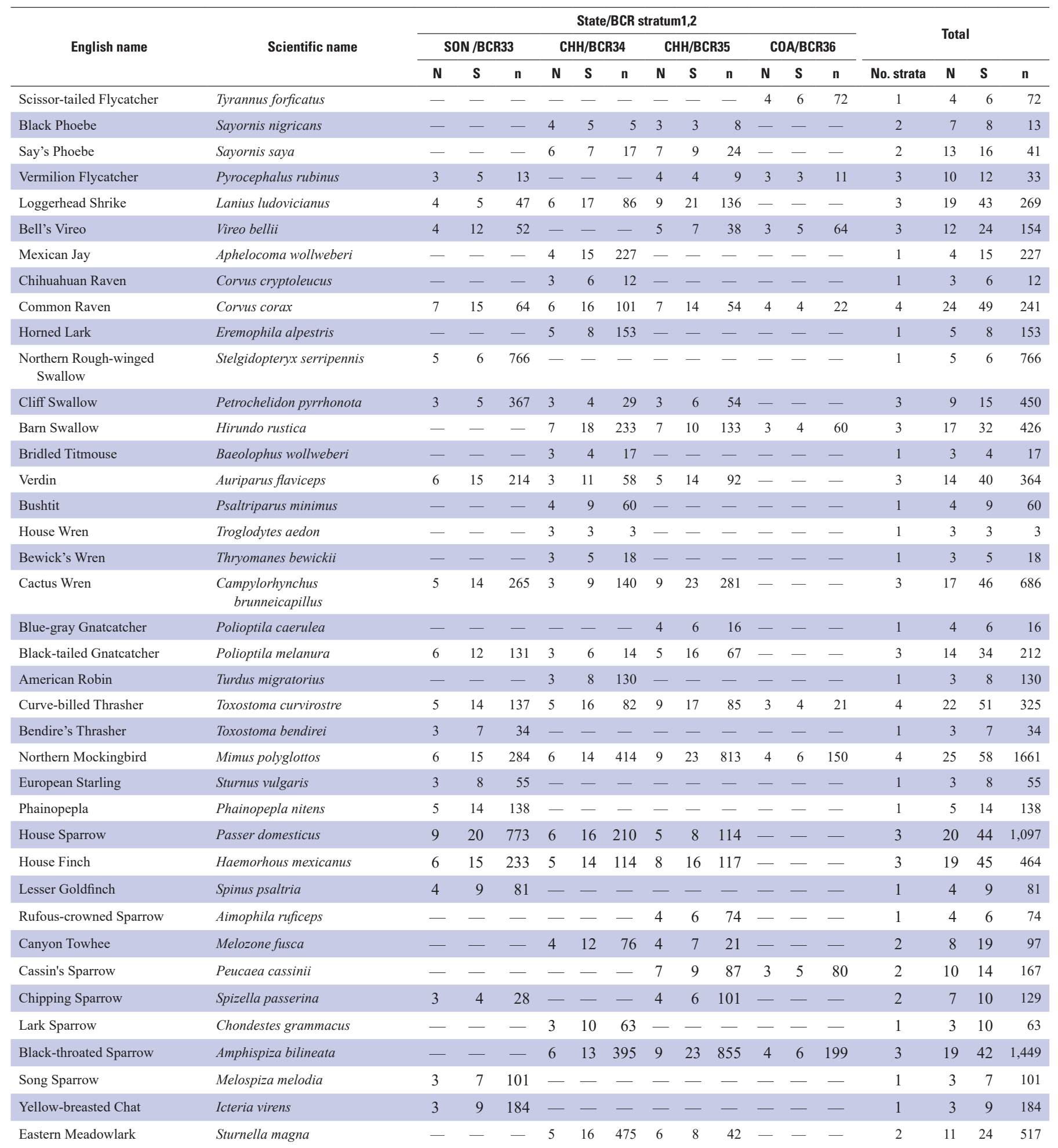


Table 6. Data from Breeding Bird Survey Routes in Mexico that would meet the absolute minimum (but not sufficient) requirement for inclusion in trend analyses according to methods typically used by the U.S. Geological Survey for United States/Canada Breeding Bird Survey analyses. This list includes 1,789 records of 95 potentially breeding species detected on three or more routes in at least one State/Bird Conservation Region stratum, after first removing records from routes that failed to meet all quality-control criteria (table 1.2). The four listed strata include at least one species reported from three or more routes. Tallies show the number of routes (N) and surveys (S) each taxon was reported from, as well as the total number of individuals reported (n).-Continued

[No., number of; BCR, Bird Conservation Region; A “_- “ indicates there are no data or insufficient data $(\mathrm{N}<3)$ ]

\begin{tabular}{|c|c|c|c|c|c|c|c|c|c|c|c|c|c|c|c|c|c|}
\hline \multirow{3}{*}{ English name } & \multirow{3}{*}{ Scientific name } & \multicolumn{12}{|c|}{ State/BCR stratum1,2 } & \multirow{2}{*}{\multicolumn{4}{|c|}{ Total }} \\
\hline & & \multicolumn{3}{|c|}{ SON /BCR33 } & \multicolumn{3}{|c|}{ CHH/BCR34 } & \multicolumn{3}{|c|}{ CHH/BCR35 } & \multicolumn{3}{|c|}{ COA/BCR36 } & & & & \\
\hline & & $\mathbf{N}$ & S & $n$ & $\mathbf{N}$ & $\mathbf{S}$ & n & $\mathbf{N}$ & s & $\mathbf{n}$ & $\mathbf{N}$ & S & $\mathrm{n}$ & No. strata & $\mathbf{N}$ & S & $n$ \\
\hline Orchard Oriole & Icterus spurius & 3 & 8 & 93 & - & - & - & - & - & - & - & - & - & 1 & 3 & 8 & 93 \\
\hline Hooded Oriole & Icterus cucullatus & - & - & - & - & - & - & - & - & - & 3 & 5 & 20 & 1 & 3 & 5 & 20 \\
\hline Bullock's Oriole & Icterus bullockii & - & - & - & 3 & 3 & 4 & - & - & - & - & - & - & 1 & 3 & 3 & 4 \\
\hline Red-winged Blackbird & Agelaius phoeniceus & 6 & 11 & 818 & - & - & - & - & - & - & - & - & - & 1 & 6 & 11 & 818 \\
\hline Bronzed Cowbird & Molothrus aeneus & 3 & 3 & 50 & - & - & - & - & - & - & - & - & - & 1 & 3 & 3 & 50 \\
\hline Brown-headed Cowbird & Molothrus ater & 5 & 13 & 158 & 4 & 10 & 26 & 7 & 9 & 48 & 3 & 5 & 43 & 4 & 19 & 37 & 275 \\
\hline Great-tailed Grackle & Quiscalus mexicanus & 8 & 19 & 712 & 6 & 13 & 63 & 4 & 5 & 43 & - & - & - & 3 & 18 & 37 & 818 \\
\hline Common Yellowthroat & Geothlypis trichas & 3 & 3 & 23 & - & - & - & - & - & - & - & - & - & 1 & 3 & 3 & 23 \\
\hline Blue Grosbeak & Passerina caerulea & - & - & - & 5 & 15 & 144 & 9 & 23 & 228 & 3 & 5 & 34 & 3 & 17 & 43 & 406 \\
\hline Painted Bunting & Passerina ciris & - & - & - & - & - & - & - & - & - & 4 & 6 & 45 & 1 & 4 & 6 & 45 \\
\hline
\end{tabular}

'State abbreviations: SON, Sonora; CHH, Chihuahua; COA, Coahuila.

${ }^{2}$ BCRs: 33, Sonoran and Mojave Deserts; 34, Sierra Madre Occidental; 35, Chihuahuan Desert; 36, Tamaulipan Brushlands.

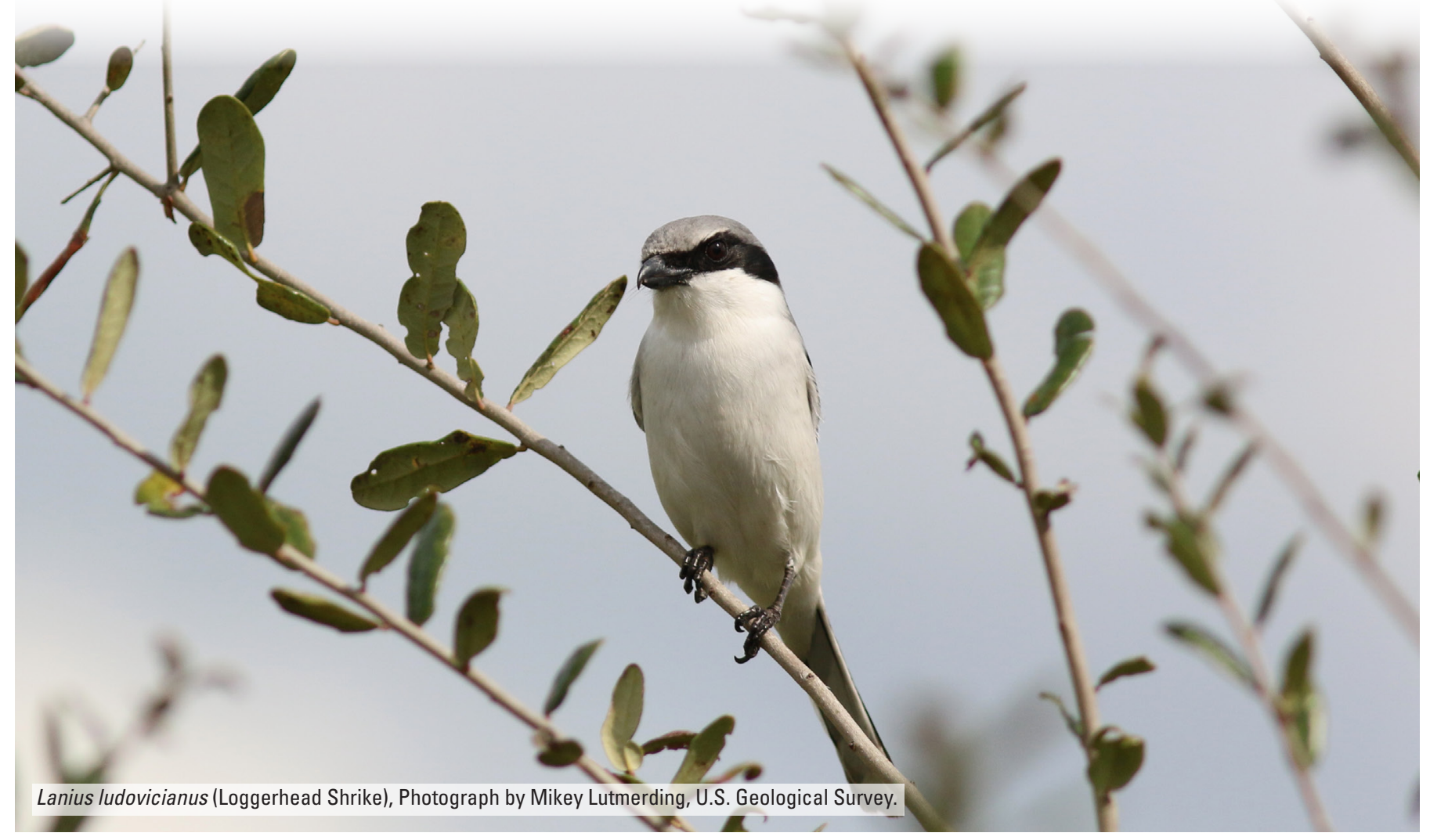


131 (table 4). The inclusion of these additional 53 surveys would not measurably improve the prospects for conducting meaningful analyses because even without applying qualitycontrol criteria, sample sizes do not meet the minimum suggested requirements in any strata (table 2 ).

\section{Conclusions}

The number of Mexican BBS surveys conducted over the first 11 years of the project have produced insufficient data for population trend analyses, even if the date window criterion is disregarded. None of the strata meet the suggested minimum sample size requirement, and most routes have not been consistently surveyed on an annual basis. Efficiency could be improved through better adherence to quality-control criteria, and sample sizes per stratum could be increased by aggregating selected strata, but this would not change the fact that most routes have not been consistently surveyed on an annual basis. Considering these deficiencies, continuing to collect data in the current manner and at the current rate will not produce enough data for trend analyses in the foreseeable future.

If a commitment is made to greatly increase the amount of data collected from new and existing routes, repeat most surveys annually, improve adherence to quality-control criteria, and possibly focus efforts in a limited number of priority focal strata, then enough data may eventually be available to reliably estimate population trends for at least the more commonly encountered species.

\section{Concluding Remarks}

The Breeding Bird Survey (BBS) is the primary source of population trend information for North American birds in the United States and Canada, and the results have many uses in research and management. The Mexican BBS program was initiated in 2008 with the goal of producing information for northern Mexico that is of similar quality to data collected in the United States and Canada. All data from Mexico collected during 2008-18 were evaluated, and the results indicate that the data are deficient in several ways.

- Some strata have no surveyed routes, and most strata with surveyed routes have very small sample sizes; moreover, yearly repetition of surveys has been inadequate.

- Volunteer participation has been limited, and it may be difficult to recruit and retain additional observers. This is a matter of safety and security, as well as training and resources.

- Two-thirds of the surveys conducted failed to meet all quality-control criteria, and the date window criterion is problematic. Protracted and asynchronous breeding at southern latitudes make it unlikely that a narrowly defined date window can be identified that encapsulates the breeding activity of most of the species. But expanding the date window would result in the reporting of more non-breeding birds, leading to higher within-species variation in detection probabilities. This highlights a fundamental limitation of the BBS methodology for monitoring population change for many Mexican species.

- Vetting data to identify records of misidentified and non-breeding species requires regional species lists that include phenological information about breeding. The development and refinement of these lists could be a product of the Mexican BBS, but a considerable amount of effort will be required to produce them.

- The data available through 2018 are inadequate for trend analysis. Continued collection of data at the current rate may never yield sufficient data for analysis. Meaningful analyses may require a substantial increase in effort.

Considering these results and the resource commitments necessary to run the program, an assessment must be made regarding the costs and benefits of continuing the program. Such an assessment must consider the challenges associated with collecting enough data for analysis and also address the feasibility of meeting these challenges. Even if obstacles to eventually achieving adequate sample sizes are not considered insurmountable, it would nonetheless be worth considering the value of data products that can be obtained in the short term. Dunn and others (2005) recognized that monitoring programs that don't provide trend information in the short-term may be of value if they contribute to the assessment of current population status and provide a baseline for future comparison. Similarly, Mexican BBS data are already contributing to our understanding of distribution patterns, and the data in this report may be useful for deciding if such data products are of sufficient value to justify the sustained investments required until enough data are available for trend analyses. But because the standard BBS protocols may not provide a practical solution for acquiring population data, there also remains a need to investigate alternative sampling protocols for Mexico (U.S. Geological Survey and Canadian Wildlife Service, 2020).

Ultimately a decision to continue investing in the Mexican BBS program in its current form will depend upon the perceived value of any short-term products; the degree of confidence that the expected long-term results will be achievable; and a willingness and ability to commit the programmatic, financial, and logistic resources required to sustain participation until longer-term benchmarks for success can be achieved. Moreover, if alternative methods of data collection appear to be preferable, we must consider how the alternative methods would be implemented, by whom, on what timeline, and at what cost. The information presented in this report is intended to contribute to this decision-making process. 


\section{References Cited}

Avibase, 2018, Avibase-the world bird database, accessed October 3, 2018, at https://avibase.bsc-eoc.org/avibase. jsp?lang $=\mathrm{EN}$.

Beittel, J.S., 2018, Mexico: Organized Crime and Drug Trafficking Organizations: Congressional Research Service Report 7-5700, accessed April 19, 2019, at https://crsreports.congress.gov/product/pdf/R/R41576/34.

Berlanga, H., Kennedy, J.A., Rich, T.D., Arizmendi, M.C., Beardmore, C.J., Blancher, P.J., Butcher, G.S., Couturier, A.R., Dayer, A.A., Demarest, D.W., Easton, W.E., Gustafson, M., Iñigo-Elias, E., Krebs, E.A., Panjabi, A.O., Rodríguez Contreras, V., Rosenberg, K.V., Ruth, J.M., Santana Castellón, E., Vidal, R.Ma., and Will, T., 2010, Saving Our Shared Birds - Partners in Flight Tri-National Vision for Landbird Conservation: Ithaca, N.Y., Cornell Lab of Ornithology.

Berlanga, H., Rodríguez-Contreras, V., Oliveras de Ita, A., Escobar, M., Rodríguez, L., Vieyra, J., and Vargas, V., 2008, Red de Conocimientos sobre las Aves de México (AVESMX): CONABIO, accessed November 17, 2018, at http://avesmx.conabio.gob.mx/Inicio.html.

Blake, J.G., 1992, Temporal variation in point counts of birds in a lowland wet forest in Costa Rica: The Condor, v. 94, no. 1, p. 265-275. [Also available at https://doi.org/10.2307/1368816.]

Calderón, L., Ferreira, O.R., and Shirk, D.A., 2018, Drug violence in Mexico: Data and analysis through 2017Justice in Mexico: San Diego, Calif., University of San Diego, Department of Political Science \& International Relations, 56 p., accessed July 29, 2019, at https://justiceinmexico.org/2018-drug-violence-mexicoreport/.

Consejo Internacional para la Preservación de las Aves en México (CIPAMEX), 2003, Homepage Publication, accessed September 13, 2018, at https://www.iztacala.unam. $\mathrm{mx} / \mathrm{wwwcampus/cipamex/principal.html.}$

Cornell Lab of Ornithology, 2018a, All About Birds: Ithaca, N.Y., Cornell Lab of Ornithology, accessed October 10, 2018, at https://www.allaboutbirds.org/news/.

Cornell Lab of Ornithology, 2018b, eBird: Ithaca, N.Y., Cornell Lab of Ornithology, accessed March 8, 2019, at https://ebird.org/home.

Cornell Lab of Ornithology, 2018c, Neotropical Birds: Ithaca, N.Y., Cornell Lab of Ornithology, accessed March 8, 2018, at https://neotropical.birds.cornell.edu/Species-Account/ $\mathrm{nb} /$ home. [Site information directly accessible at https://birdsoftheworld.org/bow/species.]
Douglas, M.W., Maddox, R.A., Howard, K., and Reyes, S., 1993, The Mexican monsoon: Journal of Climate, v. 6, no. 8, p. 1665-1677. [Also available at https://doi.org/10.1175/1520-0442(1993)006<1665:TMM> 2.0.CO;2.]

Dunn, E.H., Altman, B.L., Bart, J., Beardmore, C.J., Berlanga, H., Blancher, P.J., Butcher, G.S., Demarest. D.W., Dettmers, R., Hunter, W.C., Iñigo-Elias, E.E., Panjabi, A.O., Pashley, D.N., Ralph, C.J., Rich, T.D., Rosenberg, K.V., Rustay, C.M., Ruth, J.M., and Will, T.C., 2005, High priority needs for range-wide monitoring of North American landbirds: Partners in Flight Technical Series, No. 2, September 2005.

Dunn, J.L., and Alderfer, J., 2017, Field guide to the birds of North America 7th ed.: Washington, D.C., National Geographic Society, $591 \mathrm{p}$.

Erickson, R.A., Carmona, R., Ruiz-Campos, G., Iliff, M.J., and Billings, M.J., 2013, Annotated Checklist of the Birds of Baja California and Baja California Sur, (2d ed.): North American Birds, v. 66, no. 4, p. 582-613.

Howell, S.N.G., and Webb, S., 1995, A guide to the birds of Mexico and northern Central America: Oxford, U.K., Oxford University Press, $851 \mathrm{p}$.

iNaturalist, 2018, accessed October 17, 2018, at https://www.inaturalist.org/.

Leu, M., and Thompson, C.W., 2002, The potential importance of migratory stopover sites as flight feather molt staging areas-A review for neotropical migrants: Biological Conservation, v. 106, no. 1, p. 45-56. [Also available at https://doi.org/10.1016/S0006-3207(01)00228-2.]

Link, W.A., and Sauer, J.R., 1998, Estimating population change from count data-Application to the North American Breeding Bird Survey: Ecological Applications, v. 8, no. 2, p. 258-268. [Also available at https://doi.org/10.1890/10510761(1998)008[0258:EPCFCD]2.0.CO;2.]

North American Bird Conservation Initiative, 2016, The State of North America's Birds 2016: Ottawa, Ontario, Canada, Environment and Climate Change Canada, 8 p. [Also available at https://www.stateofthebirds.org/2016.]

O’Connor, R.J., Dunn, E., Johnson, D.H., Jones, S.L., Petit, D., Pollock, K., Smith, C.R., and Welling, E., 2000, A programmatic review of the North American Breeding Bird Survey: Report of a peer review panel to the U.S. Geological Survey: U.S. Geological Survey, Patuxent Wildlife Research Center, February, 2000. [Also available at https://www.pwrc.usgs. gov/BBS/bbsreview/bbsfinal.pdf/.] 
Panjabi, A.O., Blancher, P.J., Easton, W.E., Stanton, J.C., Demarest, D.W., Dettmers, R., and Rosenberg, K.V., 2017, The Partners in Flight Handbook on Species Assessment. Version 2017-Partners in Flight Technical Series No. 3. Brighton, Colo., Bird Conservancy of the Rockies, 35 p. [Also available at https:/www.birdconservancy.org/ resource-center/publications/.]

Pardieck, K., 2008, Expanding the North American Breeding Bird Survey into Mexico: PWRC Fact Sheet 2008-42.

Pardieck, K.L., and Sauer, J.R., 2000, The 1995-1999 summary of the North American Breeding Bird Survey: Bird Populations, v. 5, p. 30-48.

Pardieck, K.L., and Ziolkowski, D.J., Jr., 2009, North American Breeding Bird Survey Bibliography: U.S. Geological Survey, accessed May 29, 2020, at https://www.pwrc.usgs.gov/BBS/Bibliography/.

Pardieck, K.L., Ziolkowski Jr., D.J., Lutmerding, M., Aponte, V., and Hudson, M-A.R., 2019, North American Breeding Bird Survey Dataset 1966-2018, vers. 2018.0: U.S. Geological Survey, accessed May 29, 2019, at https://doi.org/10.5066/P9HE8XYJ.

Peterjohn, B.G., 1994, The North American Breeding Bird Survey: Birding, v. 26, p. 386-398.

Peterjohn, B.G., Sauer, J.R., and Link, W.A., 1996, The 1994 and 1995 summary of the North American Breeding Bird Survey: Bird Populations, v. 3, p. 48-66.

Pyle, P., Leitner, W.A., Lozano-Angulo, L., Avilez-Teran, F., Swanson, H., Limón, E.G., and Chambers, M.K., 2009, Temporal, spatial, and annual variation in the occurrence of molt-migrant passerines in the Mexican monsoon region: The Condor, v. 111, no. 4, p. 583-590. [Also available at https://doi.org/10.1525/cond.2009.090085.]

Rich, T.D., Beardmore, C.J., Berlanga, H., Blancher, P.J., Bradstreet, M.S.W., Butcher, G.S., Demarest, D.W., Dunn, E.H., Hunter, W.C., Iñigo-Elias, E.E., Kennedy, J.A., Martell, A.M., Panjabi, A.O., Pashley, D.N., Rosenberg, K.V., Rustay, C.M., Wendt, J.S., and Will, T.C., 2004, Partners in Flight North American Landbird Conservation Plan: Ithaca, N.Y., Cornell Lab of Ornithology, 37 p. [Also available at https://partnersinflight.org/resources/north-american-landbird-conservation-plan/.]

Robbins, C.S., Bystrak, D., and Geissler, P.H., 1986, The Breeding Bird Survey: Its first fifteen years, 1965-1979: U.S. Fish and Wildlife Service Resource Publication 157.

Rodewald, P., ed., 2015, The Birds of North America: Ithaca, N.Y., Cornell Laboratory of Ornithology, accessed Nov. 13, 2018, at https://birdsna.org. [Site information directly accessible at https://birdsoftheworld.org/bow/home.]
Rodríguez-Contreras, V., Berlanga, H., and Duberstein, J., 2014, Expanding the Breeding Bird Survey (BBS) to Northern Mexico-Worth and Effort: NABCI All-Bird Bulletin, Fall 2014, p. 6-7, accessed June 24, 2019, at http://www.nabci-us.org/assets/bulletin/bulletin-fall2014.pdf.

Rohwer, S., Butler, L.K., and Froehlich, D., 2005, Ecology and demography of east-west differences in molt scheduling of neotropical migrant passerines, in Greenberg, R., and Marra, P.P., eds., Birds of Two Worlds - The Ecology and Evolution of Migration: Baltimore, Md., Johns Hopkins University Press, p. 87-105.

Rohwer, S., Hobson, K.A., and Rohwer, V.G., 2009, Migratory double breeding in Neotropical migrant birds: Proceedings of the National Academy of Sciences of the United States of America, v. 106, no. 45, p. 19050-19055. [Also available at https://doi.org/10.1073/pnas.0908121106.]

Rosenberg, K.V., Blancher, P.J., Stanton, J.C., and Panjabi, A.O., 2017, Use of North American Breeding Bird Survey Data in avian conservation assessments - The Condor: Ornithological Applications, v. 119, no. 3, p. 594-606, accessed June 24, 2019 at https://doi.org/10.1650/CONDOR-17-57.1.]

Rosenberg, K.V., Kennedy, J.A., Dettmers, R., Ford, R.P., Reynolds, D., Alexander, J.D., Beardmore, C.J., Blancher, P.J., Bogart, R.E., Butcher, G.S., Camfield, A.F., Couturier, A., Demarest, D.W., Easton, W.E., Giocomo, J.J., Keller, R.H., Mini, A.E., Panjabi, A.O., Pashley, D.N., Rich, T.D., Ruth, J.M., Stabins, H., Stanton, J., and Will, T., 2016, Partners in Flight Landbird Conservation Plan-2016 Revision for Canada and Continental United States: Partners in Flight Science Committee, 119 p., accessed June 24, 2019 at https://partnersinflight.org/wp-content/uploads/2016/08/ pif-continental-plan-final-spread-double-spread.pdf.

Santana, C.E., 2005, A context for bird conservation in México-Challenges and opportunities: U.S. Department of Agriculture, Forest Service General Technical Report PSW-GTR-191

Sauer, J.R., Fallon, J.E., and Johnson, R., 2003, Use of North American Breeding Bird Survey data to estimate population change for bird conservation regions: The Journal of Wildlife Management, v. 67, no. 2, p. 372-389. [Also available at https://doi.org/10.2307/3802778.]

Sauer, J.R., Link, W.A., Fallon, J.E., Pardieck, K.L., and Ziolkowski, D.J., Jr., 2013, The North American Breeding Bird Survey 1966-2011-Summary analysis and species accounts: North American Fauna, v. 79, p. 1-32., accessed June 24, 2019 at https://doi.org/10.3996/nafa.79.0001.]

Sauer, J.R., Niven, D.K., Hines, J.E., Ziolkowski, D.J., Jr., Pardieck, K.L., Fallon, J.E., and Link, W.A., 2017a, The North American Breeding Bird Survey, Results and Analysis 1966-2015, vers. 2.07.2017: U.S. Geological Survey. 
Sauer, J.R., Niven, D.K., Pardieck, K.L., Ziolkowski, D.J., Jr., and Link, W.A., 2017b, Expanding the North American Breeding Bird Survey analysis to include additional species and regions: Journal of Fish and Wildlife Management, v. 8, no. 1, p. 154-172., accessed June 24, 2019 at https://doi.org/10.3996/102015-JFWM-109.]

Sauer, J.R., Pardieck, K.L., Ziolkowski, Jr., D.J., Smith, A.C., Hudson, M.-A.R., Rodríguez, V., Berlanga, H., Niven, D.K., and Link, W.A., 2017c, The first 50 years of the North American Breeding Bird Survey: The Condor-Ornithological Applications, v. 119, p. 576-593.

Sauer, J.R., Peterjohn, B.G., and Link, W.A., 1994, Observer differences in the North American Breeding Bird Survey: The Auk, v. 111, no. 1, p. 50-62. [Also available at https://doi.org/10.2307/4088504.]

Short, L.L., 1974, Nesting of southern Sonoran birds during the summer rainy season: The Condor, v. 76, no. 1, p. 21-32. [Also available at https://doi.org/10.2307/1365981.

U.S. Department of State, 2008, 4/15/2008 Travel Advisories, Travel Alert: Mexico, accessed February 26, 2021 at https://www.osac.gov/Country/Mexico/Content/Detail/ Report/8a787e98-9d2b-4375-9de4-15f4acddbdb4.

U.S. Department of State, 2021, Mexico Travel Advisory, accessed February 12, 2021 at https://ravel.state.gov/ content/travel/en/traveladvisories/traveladvisories/mexicotravel-advisory.html.
U.S. Fish and Wildlife Service, 2021, Migratory Bird Joint Ventures: Conserving Birds and their Habitats Throughout North America, accessed February 10, 2021 at https:/www.fws.gov/birds/management/bird-conservationpartnership-and-initiatives/migratory-bird-joint-ventures.php.

U.S. Geological Survey, 2007, Strategic plan for the North American Breeding Bird Survey: 2006-2010: U.S. Geological Survey Circular 1307, 19 p. [Also available at https://doi.org/10.3133/cir1307.]

U.S. Geological Survey and Canadian Wildlife Service, 2020, Strategic Plan for the North American Breeding Bird Survey, 2020-30: U.S. Geological Survey Circular 1466, 10 p., accessed February 10, 2021, at https://doi.org/10.3133/ cir1466. [Supersedes USGS Circular 1307.]

U.S. Geological Survey and Mexican National Commission for the Knowledge and Use of Biodiversity, 2021, The North American Breeding Bird Survey in Mexico, 20082018 - unprocessed data: U.S. Geological Survey data release, https://www.doi.org/10.5066/P9L4KBDC.

U.S. NABCI Committee, 2000, North American Bird Conservation Initiative: Bird Conservation Region Descriptions: U.S. NABCI, 44 p., accessed June 24, 2019, at https://www.birdscanada.org/bird-science/nabci-bird-conservation-regions./

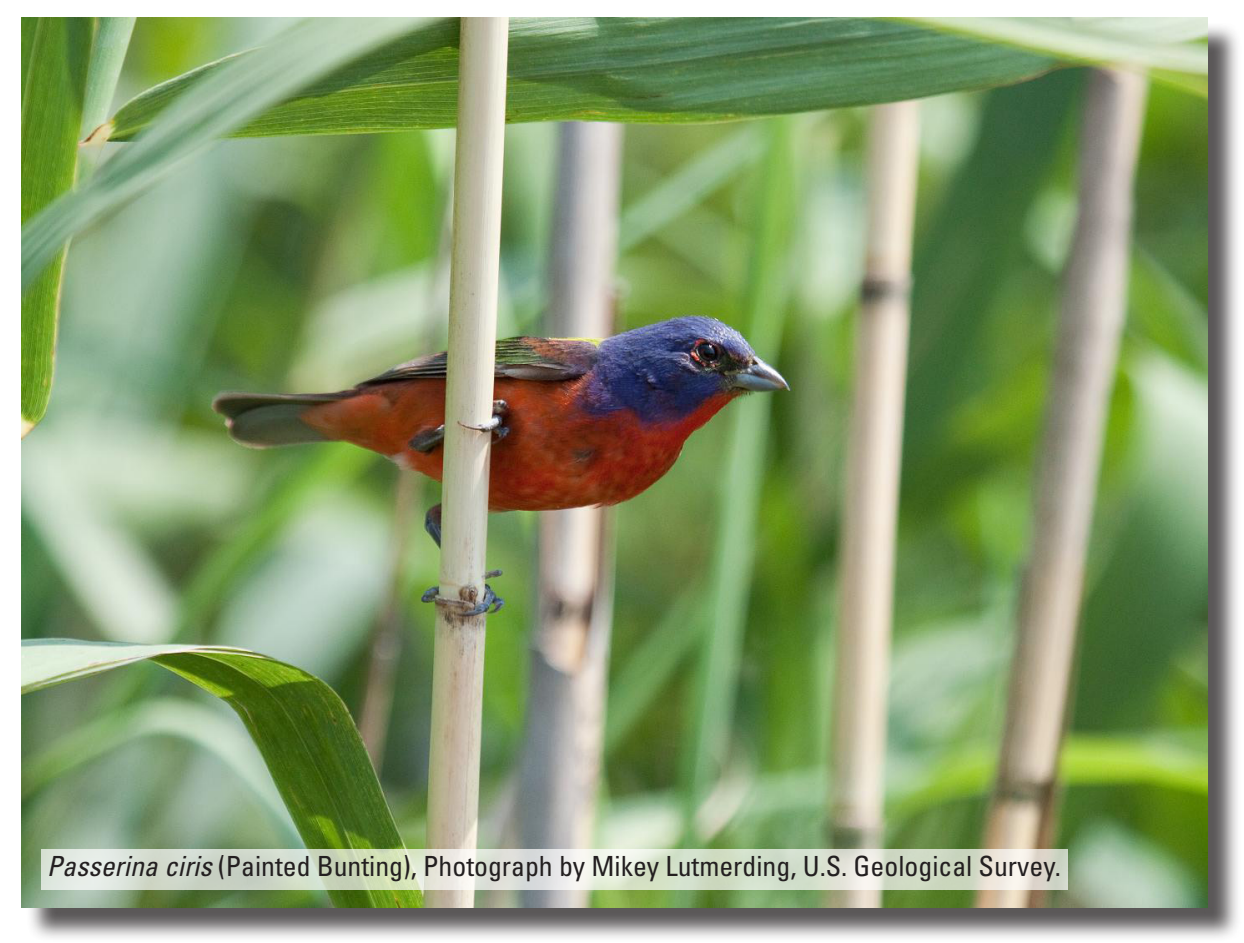


Appendix 1 


\section{Appendix 1. Summary of the Data Used in This Report}

The Breeding Bird Survey data available for this report are summarized in three tables that identify which surveys met or failed to meet quality - control criteria discussed in the text of this report. Information about all 68 Mexican routes surveyed at least once, including route name, location, and years surveyed, are included in table 1.1.

A total of 252 surveys were conducted on these 68 routes, and the circumstances and conditions under which these surveys were conducted are presented in table 1.2, along with flags identifying which surveys met various quality - control criteria. Table 1.3 presents strata - specific summaries of the bird taxa reported for the 252 Mexican surveys, along with a preliminary categorization of the breeding status of each taxon in each State/Bird Conservation Region stratum.

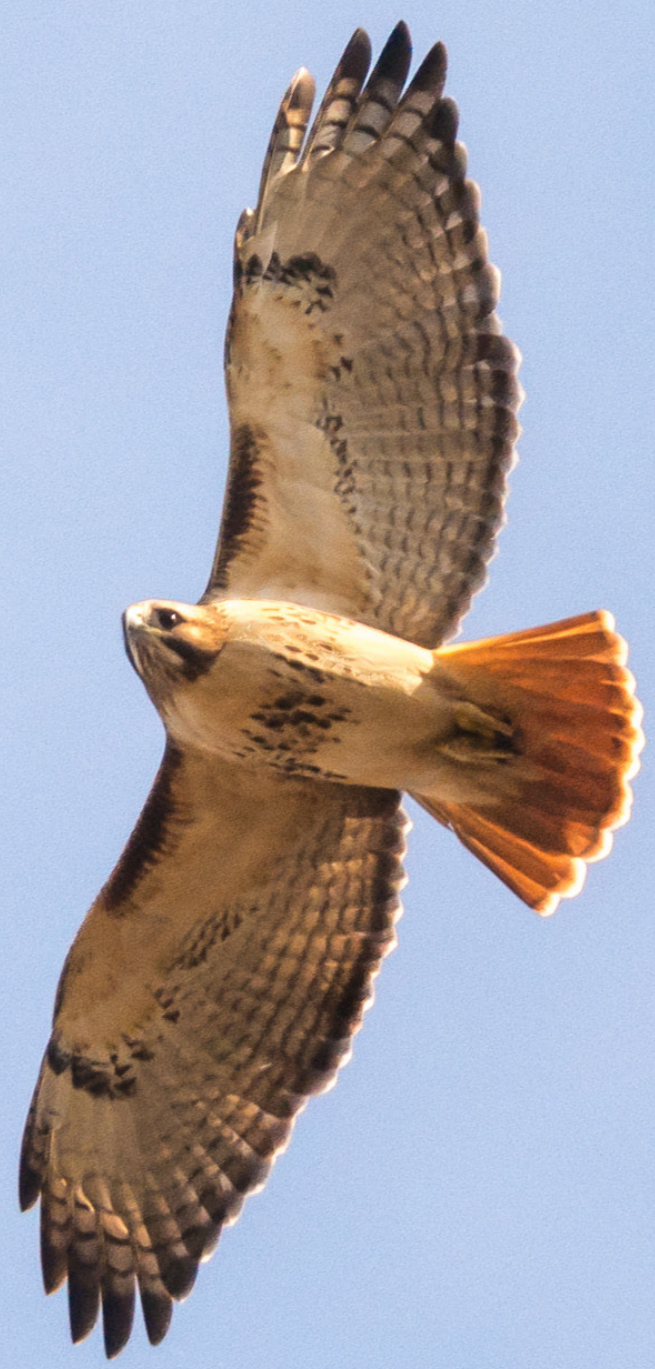


Table 1.1 Mexican Breeding Bird Survey routes surveyed at least once during 2008-18.

[BCR, Bird Conservation Region; Route, route identifier code; latitude and longitude are in decimal degrees; No., number of; OBS, observer; Values in columns 2008 through 2018 indicate which observer conducted the survey in a particular year $(1=\mathrm{OBS} 1,2=\mathrm{OBS} 2,3=\mathrm{OBS} 3) ;-$, no data; The numbers under OBS1, OBS2 and OBS3 are the unique observer numbers assigned by BBS that identify which observers conducted the surveys]

\begin{tabular}{|c|c|c|c|c|c|c|c|c|c|c|c|c|c|c|c|c|c|c|c|c|}
\hline \multirow{2}{*}{ State $^{1}$} & \multirow{2}{*}{$\mathrm{BCR}^{2}$} & \multirow{2}{*}{ Route } & \multirow{2}{*}{ Route name } & \multicolumn{2}{|c|}{ Starting point } & \multirow{2}{*}{2008} & \multirow{2}{*}{2009} & \multirow{2}{*}{2010} & \multirow{2}{*}{2011} & \multirow{2}{*}{2012} & \multirow{2}{*}{2013} & \multirow{2}{*}{2014} & \multirow{2}{*}{2015} & \multirow{2}{*}{2016} & \multirow{2}{*}{2017} & \multirow{2}{*}{2018} & \multirow{2}{*}{$\begin{array}{l}\text { No. years } \\
\text { surveyed }\end{array}$} & \multirow{2}{*}{ OBS1 } & \multirow{2}{*}{ OBS2 } & \multirow{2}{*}{ OBS3 } \\
\hline & & & & Latitude & Longitude & & & & & & & & & & & & & & & \\
\hline $\mathrm{BCS}$ & 40 & 023 & Puerto Agua Verde & 25.514 & -111.067 & - & - & - & 1 & - & - & - & - & - & - & - & 1 & 1091207 & - & - \\
\hline BCS & 40 & 032 & La Paz & 24.155 & -110.263 & - & - & - & - & - & - & - & 1 & - & - & - & 1 & 1180185 & - & - \\
\hline $\mathrm{BCS}$ & 40 & 033 & San Marcos & 23.875 & -110.316 & - & - & - & - & - & - & - & 1 & - & - & - & 1 & 1180185 & - & - \\
\hline $\mathrm{BCS}$ & 42 & 038 & La Fortuna & 23.154 & -109.502 & - & - & - & - & - & - & 1 & - & - & - & - & 1 & 1030684 & - & - \\
\hline $\mathrm{BCN}$ & 32 & 004 & El Porvenir & 32.073 & -116.623 & 1 & - & - & - & - & - & - & - & - & 2 & 3 & 3 & 1091107 & 1180185 & 1041174 \\
\hline $\mathrm{BCN}$ & 33 & 007 & Miramar & 32.110 & -115.248 & - & - & - & 1 & 1 & 1 & 1 & 1 & 1 & 1 & 1 & 8 & 990849 & - & - \\
\hline $\mathrm{BCN}$ & 33 & 008 & Pangas Viejas & 32.039 & -115.081 & - & - & - & 1 & 1 & 1 & 1 & 1 & 1 & 1 & 1 & 8 & 990849 & - & - \\
\hline SON & 33 & 001 & S. Luis Rio Colorado & 32.460 & -114.702 & - & - & - & 1 & 1 & 1 & 1 & 1 & 1 & 1 & 1 & 8 & 990849 & - & - \\
\hline SON & 33 & 002 & Mesa Rica & 32.136 & -114.921 & - & - & - & - & 1 & 1 & 1 & 1 & 1 & 1 & 1 & 7 & 990849 & - & - \\
\hline SON & 33 & 004 & Sanchez Islas & 31.757 & -114.455 & - & - & - & 1 & 1 & 1 & 1 & 1 & 1 & 1 & 1 & 8 & 990849 & - & - \\
\hline SON & 33 & 005 & Golfo de Santa Clara & 31.692 & -114.501 & - & - & - & - & - & 1 & 1 & 1 & 1 & 1 & 1 & 6 & 990849 & - & - \\
\hline SON & 33 & 009 & Las Conchas & 31.306 & -113.531 & - & - & - & - & - & 1 & - & 1 & - & - & - & 2 & 970406 & - & - \\
\hline SON & 33 & 058 & Puerto Rico & 28.659 & -111.446 & - & - & - & 1 & - & - & - & - & - & - & - & 1 & 1090908 & - & - \\
\hline SON & 33 & 062 & Oritz & 28.288 & -110.709 & 1 & - & 1 & 1 & 1 & 1 & 1 & 1 & 1 & 1 & 1 & 10 & 1030610 & - & - \\
\hline SON & 33 & 070 & Belem Rio Yaqui & 27.770 & -110.439 & - & - & - & 1 & 1 & - & 1 & 1 & 1 & 1 & 1 & 7 & 1080633 & - & - \\
\hline SON & 33 & 072 & Democracia & 27.292 & -110.205 & - & - & - & 1 & 1 & - & 1 & 1 & 1 & 1 & 1 & 7 & 1080633 & - & - \\
\hline SON & 43 & 075 & Bachomobampo & 27.434 & -109.435 & - & - & - & - & - & - & - & - & - & - & 1 & 1 & 1091340 & - & - \\
\hline $\mathrm{CHH}$ & 34 & 002 & San Basilio & 31.080 & -108.418 & - & 1 & 1 & - & - & - & - & - & - & - & - & 2 & 1030635 & - & - \\
\hline $\mathrm{CHH}$ & 34 & 011 & Monte Verde & 30.913 & -108.710 & - & 1 & 1 & - & - & - & - & - & - & - & - & 2 & 1030635 & - & - \\
\hline $\mathrm{CHH}$ & 34 & 015 & $\begin{array}{c}\text { Nuevo Casas } \\
\text { Grandes }\end{array}$ & 30.461 & -107.916 & - & 1 & 1 & - & - & - & - & - & - & - & - & 2 & 1030635 & - & - \\
\hline $\mathrm{CHH}$ & 34 & 033 & La Concha & 29.116 & -107.882 & - & - & - & - & 1 & - & - & - & - & - & - & 1 & 990850 & - & - \\
\hline $\mathrm{CHH}$ & 34 & 048 & Adolfo Ruiz Cortines & 28.927 & -107.507 & - & - & - & 1 & 1 & 1 & 1 & 1 & - & - & - & 5 & 1180166 & - & - \\
\hline $\mathrm{CHH}$ & 34 & 051 & Rancho de Santiago & 28.346 & -107.182 & - & - & - & 1 & - & 1 & 1 & 1 & - & - & - & 4 & 1180166 & - & - \\
\hline $\mathrm{CHH}$ & 34 & 054 & El Sordo & 28.324 & -106.030 & - & 1 & 1 & 1 & 1 & 1 & 1 & 1 & 1 & 1 & 1 & 10 & 1180166 & - & - \\
\hline $\mathrm{CHH}$ & 34 & 055 & Aguilares & 28.150 & -106.215 & - & - & - & - & - & - & - & - & - & - & 1 & 1 & 1160490 & - & - \\
\hline $\mathrm{CHH}$ & 34 & 069 & Cusarare & 27.610 & -107.550 & - & - & 1 & - & 1 & - & - & - & - & - & - & 2 & 1151411 & - & - \\
\hline $\mathrm{CHH}$ & 34 & 070 & La Bufa & 27.114 & -107.598 & - & - & 1 & - & - & - & - & - & - & - & - & 1 & 1151411 & - & - \\
\hline $\mathrm{CHH}$ & 34 & 089 & Laguna Juanota & 26.476 & -106.482 & - & - & 1 & - & 1 & - & - & - & - & - & - & 2 & 1151411 & - & - \\
\hline $\mathrm{CHH}$ & 35 & 025 & Los Pinos & 30.368 & -105.237 & - & - & - & 1 & 1 & 1 & 1 & 1 & - & - & 1 & 6 & 1180166 & - & - \\
\hline $\mathrm{CHH}$ & 35 & 039 & Placer de Guadalupe & 29.164 & -105.381 & - & - & - & 1 & 1 & 1 & 1 & 1 & - & - & 1 & 6 & 1180166 & - & - \\
\hline
\end{tabular}


Table 1.1 Mexican Breeding Bird Survey routes surveyed at least once during 2008-18.-Continued

[BCR, Bird Conservation Region; Route, route identifier code; latitude and longitude are in decimal degrees; No., number of; OBS, observer; Values in columns 2008 through 2018 indicate which observer conducted the survey in a particular year $(1=$ OBS1, 2 = OBS2, 3 = OBS3); - , no data; The numbers under OBS1, OBS2 and OBS3 are the unique observer numbers assigned by BBS that identify which observers conducted the surveys]

\begin{tabular}{|c|c|c|c|c|c|c|c|c|c|c|c|c|c|c|c|c|c|c|c|c|}
\hline \multirow{2}{*}{ State $^{1}$} & \multirow{2}{*}{$\mathrm{BCR}^{2}$} & \multirow{2}{*}{ Route } & \multirow{2}{*}{ Route name } & \multicolumn{2}{|c|}{ Starting point } & \multirow{2}{*}{2008} & \multirow{2}{*}{2009} & \multirow{2}{*}{2010} & \multirow{2}{*}{2011} & \multirow{2}{*}{2012} & \multirow{2}{*}{2013} & \multirow{2}{*}{2014} & \multirow{2}{*}{2015} & \multirow{2}{*}{2016} & \multirow{2}{*}{2017} & \multirow{2}{*}{2018} & \multirow{2}{*}{$\begin{array}{l}\text { No. years } \\
\text { surveyed }\end{array}$} & \multirow{2}{*}{ OBS1 } & \multirow{2}{*}{ OBS2 } & \multirow{2}{*}{ OBS3 } \\
\hline & & & & Latitude & Longitude & & & & & & & & & & & & & & & \\
\hline $\mathrm{CHH}$ & 35 & 042 & Barrio Montoya & 29.375 & -104.148 & - & - & - & 1 & 1 & 1 & 2 & 1 & - & - & - & 5 & 1180166 & 1110211 & - \\
\hline $\mathrm{CHH}$ & 35 & 056 & El Potrero & 28.780 & -105.484 & - & 1 & 1 & 1 & 1 & 1 & 1 & 1 & 1 & 1 & 1 & 10 & 1180166 & - & - \\
\hline $\mathrm{CHH}$ & 35 & 057 & El Buchar & 28.605 & -105.022 & - & - & - & - & - & 1 & - & - & - & - & - & 1 & 1091260 & - & - \\
\hline $\mathrm{CHH}$ & 35 & 058 & La Regina & 28.417 & -105.454 & - & 1 & 1 & - & 1 & 1 & 1 & 1 & 1 & 1 & 1 & 9 & 1060368 & - & - \\
\hline $\mathrm{CHH}$ & 35 & 059 & Santa Monica & 28.108 & -105.545 & - & 1 & 1 & - & 1 & 1 & 1 & 1 & 1 & 1 & 1 & 9 & 1060368 & - & - \\
\hline $\mathrm{CHH}$ & 35 & 064 & El Oso & 28.693 & -103.523 & - & - & - & 1 & 1 & 1 & 2 & 1 & - & - & - & 5 & 1180166 & 1110211 & - \\
\hline $\mathrm{CHH}$ & 35 & 076 & Valle del Torro & 27.966 & -105.232 & - & - & - & - & - & - & 1 & 1 & - & - & 1 & 3 & 1151527 & - & - \\
\hline $\mathrm{CHH}$ & 35 & 077 & Rancho Nuevo & 27.628 & -105.293 & - & - & - & - & - & - & - & 1 & - & 1 & 1 & 3 & 1151527 & - & - \\
\hline CHH & 35 & 078 & El Tigre & 27.540 & -105.393 & - & - & - & - & - & - & 1 & 1 & 1 & 1 & 1 & 5 & 1151527 & - & - \\
\hline $\mathrm{CHH}$ & 35 & 079 & San Juan & 27.217 & -105.553 & - & - & - & - & - & - & - & 1 & - & - & 1 & 2 & 1151527 & - & - \\
\hline $\mathrm{COA}$ & 35 & 010 & El Mortero & 28.794 & -102.587 & - & - & - & - & - & 1 & - & 1 & - & - & - & 2 & 1110211 & - & - \\
\hline $\mathrm{COA}$ & 35 & 029 & $\begin{array}{l}\text { Cuatrocienegas } \\
\text { Norte }\end{array}$ & 27.007 & -102.074 & - & - & - & - & - & 1 & - & 1 & - & 1 & 1 & 4 & 1151507 & - & - \\
\hline $\mathrm{COA}$ & 35 & 039 & Cuatrocinegas Sur & 26.963 & -102.094 & - & - & - & - & - & 1 & - & 1 & - & 1 & 1 & 4 & 1151507 & - & - \\
\hline $\mathrm{COA}$ & 35 & 045 & La Campana & 26.599 & -101.797 & - & - & - & - & - & - & - & 1 & - & - & - & 1 & 1110223 & - & - \\
\hline $\mathrm{COA}$ & 35 & 052 & Parras & 25.617 & -102.161 & - & - & - & - & - & - & 1 & 2 & - & 2 & 2 & 4 & 1180168 & 1151507 & - \\
\hline $\mathrm{COA}$ & 35 & 053 & Parras Oeste & 25.453 & -102.194 & - & - & - & - & - & - & 1 & 2 & - & 2 & 2 & 4 & 1180168 & 1151507 & - \\
\hline $\mathrm{COA}$ & 35 & 055 & Piedra Blanca & 25.656 & -101.929 & - & - & - & - & - & - & 1 & 1 & - & - & 1 & 3 & 990893 & - & - \\
\hline $\mathrm{COA}$ & 35 & 056 & Norias de la Sabrina & 25.620 & -101.549 & - & - & - & - & - & - & 1 & 2 & 2 & 2 & 2 & 5 & 990893 & 1151507 & \\
\hline $\mathrm{COA}$ & 35 & 057 & General Cepeda & 25.391 & -101.079 & - & - & - & - & - & - & 1 & 1 & - & - & - & 2 & 1030657 & - & - \\
\hline $\mathrm{COA}$ & 35 & 060 & Los Angeles & 25.115 & -100.995 & - & - & - & - & - & - & 1 & 1 & - & - & - & 2 & 1030657 & - & - \\
\hline $\mathrm{COA}$ & 35 & 061 & $\begin{array}{l}\text { Cuatrocienegas } \\
\text { Oeste }\end{array}$ & 26.984 & -102.083 & - & - & - & - & - & 1 & - & 1 & - & 1 & 1 & 4 & 1151507 & - & - \\
\hline $\mathrm{COA}$ & 35 & 063 & Buñuelos & 25.062 & -101.191 & - & - & - & - & - & - & 1 & - & - & - & - & 1 & 1080586 & - & - \\
\hline $\mathrm{COA}$ & 36 & 017 & El Jaralito & 28.070 & -101.530 & - & - & - & - & - & 1 & - & 1 & - & 1 & 1 & 4 & 1110211 & - & - \\
\hline $\mathrm{COA}$ & 36 & 030 & Minas de Barroteran & 27.643 & -101.276 & - & - & - & - & - & 1 & 1 & 1 & 1 & 1 & 1 & 6 & 1110211 & - & - \\
\hline $\mathrm{COA}$ & 36 & 034 & Progreso & 27.434 & -100.984 & - & - & - & - & - & - & - & 1 & - & - & - & 1 & 1110223 & - & - \\
\hline $\mathrm{COA}$ & 36 & 062 & Santa Rosa & 29.484 & -101.367 & - & - & - & - & - & 1 & 1 & - & - & - & - & 2 & 1180168 & - & - \\
\hline NLE & 35 & 027 & La Zorra & 23.922 & -100.067 & - & - & - & - & 1 & 1 & 1 & 1 & - & - & - & 4 & 990867 & - & - \\
\hline NLE & 35 & 028 & Boquillas & 23.554 & -100.329 & - & - & - & - & - & - & 1 & - & - & - & - & 1 & 990867 & - & - \\
\hline NLE & 35 & 029 & Presa de Maltos & 23.253 & -100.392 & - & - & - & - & 1 & 1 & 1 & - & - & - & - & 3 & 990867 & - & - \\
\hline NLE & 35 & 031 & El Arco & 26.194 & -100.669 & - & - & - & - & - & - & - & 1 & - & - & - & 1 & 1180168 & - & - \\
\hline
\end{tabular}


Table 1.1 Mexican Breeding Bird Survey routes surveyed at least once during 2008-18.-Continued

[BCR, Bird Conservation Region; Route, route identifier code; latitude and longitude are in decimal degrees; No., number of; OBS, observer; Values in columns 2008 through 2018 indicate which observer conducted the survey in a particular year $(1=\mathrm{OBS} 1,2=\mathrm{OBS} 2,3=\mathrm{OBS} 3) ;-$, no data; The numbers under OBS1, OBS2 and OBS3 are the unique observer numbers assigned by BBS that identify which observers conducted the surveys]

\begin{tabular}{|c|c|c|c|c|c|c|c|c|c|c|c|c|c|c|c|c|c|c|c|c|}
\hline \multirow{2}{*}{ State $^{1}$} & \multirow{2}{*}{$\mathrm{BCR}^{2}$} & \multirow{2}{*}{ Route } & \multirow{2}{*}{ Route name } & \multicolumn{2}{|c|}{ Starting point } & \multirow{2}{*}{2008} & \multirow{2}{*}{2009} & \multirow{2}{*}{2010} & \multirow{2}{*}{2011} & \multirow{2}{*}{2012} & \multirow{2}{*}{2013} & \multirow{2}{*}{2014} & \multirow{2}{*}{2015} & \multirow{2}{*}{2016} & \multirow{2}{*}{2017} & \multirow{2}{*}{2018} & \multirow{2}{*}{$\begin{array}{c}\text { No. years } \\
\text { surveyed }\end{array}$} & \multirow{2}{*}{ OBS1 } & \multirow{2}{*}{ OBS2 } & \multirow{2}{*}{ OBS3 } \\
\hline & & & & Latitude & Longitude & & & & & & & & & & & & & & & \\
\hline NLE & 35 & 032 & Ojo de Agua & 25.857 & -100.527 & - & - & - & - & - & - & - & - & - & 1 & 1 & 2 & 990926 & - & - \\
\hline NLE & 36 & 033 & Dr. González & 25.851 & -99.933 & - & - & - & - & - & - & - & - & - & 1 & 1 & 2 & 1030720 & - & - \\
\hline NLE & 36 & 034 & Cerralvo & 26.098 & -99.619 & - & - & - & - & - & - & - & - & - & 1 & 1 & 2 & 1030720 & - & - \\
\hline NLE & 48 & 011 & Ciénega & 25.389 & -100.248 & - & - & - & - & - & 1 & - & 1 & - & - & - & 2 & 990868 & - & - \\
\hline NLE & 48 & 012 & El Castillo & 25.117 & -100.660 & - & - & - & - & - & - & 1 & 1 & - & - & - & 2 & 1180168 & - & - \\
\hline NLE & 48 & 025 & Portero de Zamora & 24.024 & -99.927 & - & - & - & - & 1 & 1 & 1 & - & - & - & - & 3 & 990867 & - & - \\
\hline TAM & 48 & 019 & José María Morelos & 23.501 & -99.352 & - & - & - & - & - & 1 & 1 & - & - & - & - & 2 & 1091256 & - & - \\
\hline TAM & 48 & 020 & Jaumave & 23.398 & -99.386 & - & - & - & - & - & 1 & 1 & - & - & - & 1 & 3 & 1091256 & - & - \\
\hline
\end{tabular}

${ }^{1}$ State abbreviations: BCS, Baja California Sur; BCN, Baja California; SON, Sonora; CHH, Chihuahua; COA, Coahuila; NLE, Nuevo León; TAM, Tamaulipas.

${ }^{2}$ BCRs: 32, Coastal California; 33, Sonoran and Mojave Deserts; 34, Sierra Madre Occidental; 35, Chihuahuan Desert; 36, Tamaulipan Brushlands; 40, Desierto de Baja California; 42, Sierra y Planicies de El Cabo; 43, Planicie Costera, Lomeríos y Cañones de Occidente; 48, Sierra Madre Oriental. 
For more information about this publication, contact:

Director, Eastern Ecological Science Center

U.S. Geological Survey

12100 Beech Forest Road

Laurel, MD

For additional information, visit: https://www.usgs.gov/centers/pwrc

Publishing support provided by the Reston Publishing Service Center 
is

D

응

$\stackrel{\circ}{\circ}$

$\stackrel{\rho}{\mathscr{\rho}}$

离

言

总

क

글

zo

?

․․․

ฏ

听

들

䍚

窟 